\author{
OAK RIDGE \\ NATIONAL LABORATORY
}

MANAGED BY UT-BATTELLE

FOR THE DEPARTMENT OF ENERGY

\title{
Results from ORNL Characterization of ZrO2-500-AK2 - Surrogate TRISO Material
}

\author{
Revision 1
}

\author{
Andrew K. Kercher \\ and John D. Hunn
}

June 2005

This report was prepared as an account of work sponsored by an agency of the United States Government. Neither the United States Government nor any agency thereof, or any of their employees, makes any warranty, expressed or implied, or assumes any legal liability or responsibility for any third party's use, or the results of such use, of any information, apparatus, product or process disclosed in this report, or represents that its use by such third party would not infringe privately owned rights. 


\section{DOCUMENT AVAILABILITY}

Reports produced after January 1, 1996, are generally available free via the U.S. Department of Energy (DOE) Information Bridge.

Web site http://www.osti.gov/bridge

Reports produced before January 1, 1996, may be purchased by members of the public from the following source.

National Technical Information Service

5285 Port Royal Road

Springfield, VA 22161

Telephone 703-605-6000 (1-800-553-6847)

TDD 703-487-4639

Fax 703-605-6900

E-mail info@ntis.fedworld.gov

Web site http://www.ntis.gov/support/ordernowabout.htm

Reports are available to DOE employees, DOE contractors, Energy Technology Data Exchange (ETDE) representatives, and International Nuclear Information System (INIS)

representatives from the following source.

Office of Scientific and Technical Information

P.O. Box 62

Oak Ridge, TN 37831

Telephone 865-576-8401

Fax 865-576-5728

E-mail reports@adonis.osti.gov

Web site http://www.osti.gov/contact.html

This report was prepared as an account of work sponsored by an agency of the United States Government. Neither the United States Government nor any agency thereof, nor any of their employees, makes any warranty, express or implied, or assumes any legal liability or responsibility for the accuracy, completeness, or usefulness of any information, apparatus, product, or process disclosed, or represents that its use would not infringe privately owned rights. Reference herein to any specific commercial product, process, or service by trade name, trademark, manufacturer, or otherwise, does not necessarily constitute or imply its endorsement, recommendation, or favoring by the United States Government or any agency thereof. The views and opinions of authors expressed herein do not necessarily state or reflect those of the United States Government or any agency thereof. 


\title{
Results from ORNL Characterization of ZrO2-500-AK2 - Surrogate TRISO Material
}

\author{
Andrew K. Kercher and John D. Hunn \\ Oak Ridge National Laboratory
}

This document is a compilation of the characterization data for the TRISO-coated surrogate particle batch designated $\mathrm{ZrO} 2-500-\mathrm{AK} 2$ that was produced at Oak Ridge National Laboratory (ORNL) as part of the Advanced Gas Reactor Fuel Development and Qualification (AGR) program. The $\mathrm{ZrO} 2-500-\mathrm{AK} 2$ material contains nominally $500 \mu \mathrm{m}$ kernels of yttria-stabilized zirconia (YSZ) coated with all TRISO layers (buffer, inner pyrocarbon, silicon carbide, and outer pyrocarbon). The $\mathrm{ZrO} 2-500-\mathrm{AK} 2$ material was created for: (1) irradiation testing in the High Flux Isotope Reactor (HFIR) and (2) limited dissemination to laboratories as deemed appropriate to the AGR program. This material was created midway into a TRISO fuel development program to accommodate a sudden opportunity to perform irradiation testing on surrogate material. While the layer deposition processes were chosen based on the best technical understanding at the time, technical progress at ORNL has led to an evolution in the perceived optimal deposition conditions since the creation of $\mathrm{ZrO} 2-500-\mathrm{AK} 2$. Thus, $\mathrm{ZrO} 2-500-\mathrm{AK} 2$ contains a reasonable TRISO microstructure, but does differ significantly from currently produced TRISO surrogates and fuel at ORNL. In this document, characterization data of the $\mathrm{ZrO} 2-500-\mathrm{AK} 2$ surrogate includes: size, shape, coating thickness, and density.

For comparison purposes, some data pertaining to a German reference fuel have been included in this report. The German reference fuel was a sample of the EUO 2358-2365 composite studied by General Atomics (GA) and referenced in GA document \#910852 "Acceptance Test Report for German Fuel Particles." 


\section{Table of Contents}

$1 \quad$ Processing Conditions __ 3

2 Coating Fractography __ 3

$3 \quad$ Measurement of Size and Shape Using Shadowgraphy__ 8

3.1 Size and shape of kernels __ 8

3.2 Size and shape of coated particles __ 8

$4 \quad$ Measurement of Coating Thicknesses __ 13

4.1 Kernel diameter _ 13

4.2 Buffer thickness __ 14

4.3 IPyC thickness _ 15

4.4 SiC thickness __ 16

4.5 OPyC thickness _ 16

4.6 Total particle radius __ 17

5 Density Measurement _ 19

$5.1 \quad \mathrm{SiC}$ density __ 19

5.2 OPyC density _ 20

$6 \quad$ Optical Anisotropy Measurements __ 22

7 SEM Analysis__ 24

7.1 SEM of coated particles __ 24

7.2 Grain size of SiC layer __ 29 


\title{
1 Processing Conditions
}

\author{
R.A. Lowden, J.H. Miller
}

The ZrO2-500-AK2 kernels were $\sim 0.5 \mathrm{~mm}$ YSZ (yttria-stabilized zirconia) grinding media sold by the TOSOH Corporation and manufactured by the Nikkato Corporation. The lot number for the YSZ grinding media was \#5230460050. The following information was measured by the manufacturer and reported in the inspection sheet associated with this specific lot: density 6.04 $\mathrm{g} / \mathrm{cm}^{3}$, hardness (HV1) $12.7 \mathrm{GPa}$, and crushing load $0.22 \mathrm{kN}$.

Kernels were coated with the different TRISO layers by chemical vapor deposition (CVD) in a fluidized bed furnace. The fluidized bed furnace had a 2 " diameter tube and a 0.125 " gas inlet diameter. The precursor loading for the coating run for $\mathrm{ZrO} 2-500-\mathrm{AK} 2$ included 55 grams of YSZ kernels and also 0.8 grams of small rods (which were produced for other studies). The kernels were fluidized in argon, and the furnace was heated to $1250^{\circ} \mathrm{C}$. Once stabilized at $1250^{\circ} \mathrm{C}$, buffer carbon was deposited for 5 minutes under a flow of $3.9 \mathrm{~L} / \mathrm{min}$ acetylene and 2.6 $\mathrm{L} / \mathrm{min}$ argon. After buffer deposition, the furnace was purged in argon under fluidizing conditions. Then, the inner pyrocarbon (IPyC) was deposited at $1250^{\circ} \mathrm{C}$ for 9 minutes under a flow of $1.05 \mathrm{~L} / \mathrm{min}$ acetylene, $1.05 \mathrm{~L} / \mathrm{min}$ propylene, and $4.9 \mathrm{~L} / \mathrm{min}$ argon. After IPyC deposition, the furnace was purged in argon under fluidizing conditions while heating up to $1400^{\circ} \mathrm{C}$. Silicon carbide was deposited at $1400^{\circ} \mathrm{C}$ for 145 minutes using precursors of hydrogen and methyl trichlorosilane (MTS), which is a liquid precursor. A bubbler with a $0.5 \mathrm{~L} / \mathrm{min}$ carrier stream of hydrogen was used to introduce MTS into the gas flow at an approximate mass flow rate of $0.841 \mathrm{~g} / \mathrm{min}$. The gas flows for $\mathrm{SiC}$ deposition were $4.75 \mathrm{~L} / \mathrm{min}$ hydrogen (including bubbler carrier stream) and $4.25 \mathrm{~L} / \mathrm{min}$ argon. The furnace was cooled down to $1250^{\circ} \mathrm{C}$ in argon under fluidizing conditions. The outer pyrocarbon $(\mathrm{OPyC})$ was deposited for 8 minutes under a flow of $1.275 \mathrm{~L} / \mathrm{min}$ acetylene, $1.275 \mathrm{~L} / \mathrm{min}$ propylene, and $5.95 \mathrm{~L} / \mathrm{min}$ argon. Then, the furnace was cooled to room temperature in argon under fluidizing conditions. The final weight of TRISO surrogate particles was about 140 grams.

\section{Coating Fractography}

\section{J.D. Hunn and N. Hashimoto}

A $\mathrm{ZrO} 2-500-\mathrm{AK} 2$ particle was crushed to fracture in order to examine the fracture surfaces. Since analysis was performed on a single particle, no claims can be made on the statistical relevance of these results. Nonetheless, it is believed that these images should be representative of fracture surfaces of $\mathrm{ZrO} 2-500-\mathrm{AK} 2$ particles. The coatings separated cleanly from the kernel. A large fragment was identified for SEM analysis in secondary electron and backscatter modes. All of the coatings remained attached to each other in the fragment (Figure 2-1), but extensive interfacial cracking was observed at the $\mathrm{SiC} / \mathrm{OPyC}$ boundary (Figure 2-5).

The buffer fracture surface was highly jagged; the fracture likely propagated predominantly through high porosity regions of the buffer (Figure 2-2). The fracture surfaces of the other layers are significantly more uniform. The IPyC and OPyC were deposited under similar conditions, 
and thus they had similar fracture surfaces (Figure 2-3). The IPyC fracture surface (Figure 2-4) and $\mathrm{OPyC}$ fracture surface (Figure 2-5) showed evidence of a nodular microstructure. Pyrocarbon deposition can occur by: (1) direct deposition onto the surface and/or (2) gas phase nucleation of carbon and subsequent deposition of the carbon nuclei onto the surface. For both the IPyC and $\mathrm{OPyC}$, the presence of a nodular microstructure indicates that a significant amount of pyrocarbon deposition occurred by gas phase nucleation and subsequent deposition.

The $\mathrm{IPyC} / \mathrm{SiC}$ interface exhibited extensive interlacing (Figure 2-4), but the $\mathrm{OPyC} / \mathrm{SiC}$ interface had no apparent interlacing and poor interfacial strength (Figure 2-5). A crack inside the particle demonstrated extensive propagation along the $\mathrm{OPyC} / \mathrm{SiC}$ interface (possibly exfoliation). During processing, the SiC deposited onto a nodular IPyC surface, which likely caused the extensive interlacing at the $\mathrm{IPyC} / \mathrm{SiC}$ interface, whereas the $\mathrm{OPyC}$ deposited onto a relatively smooth $\mathrm{SiC}$ surface, which likely caused the abrupt transition at the $\mathrm{OPyC} / \mathrm{SiC}$ interface.

Unlike the buffer, IPyC, and OPyC layers, the $\mathrm{SiC}$ layer did not fracture predominantly along microstructural features. The $\mathrm{SiC}$ fracture surface suggested a combination of intergranular and intragranular fracture (Figure 2-6). Stepped fracture surfaces, which indicate intragranular fracture, occurred in small regions. The localized nature of intragranular fracture suggested that intergranular fracture was a significant fracture mode. In comparison, the German reference fuel (Figure 2-7) had intragranular fracture that extended over longer distances, which would suggest that intergranular fracture was less significant in the German reference fuel than in the $\mathrm{ZrO} 2-$ 500-AK2 (given their similar grain size; see section 7.2).

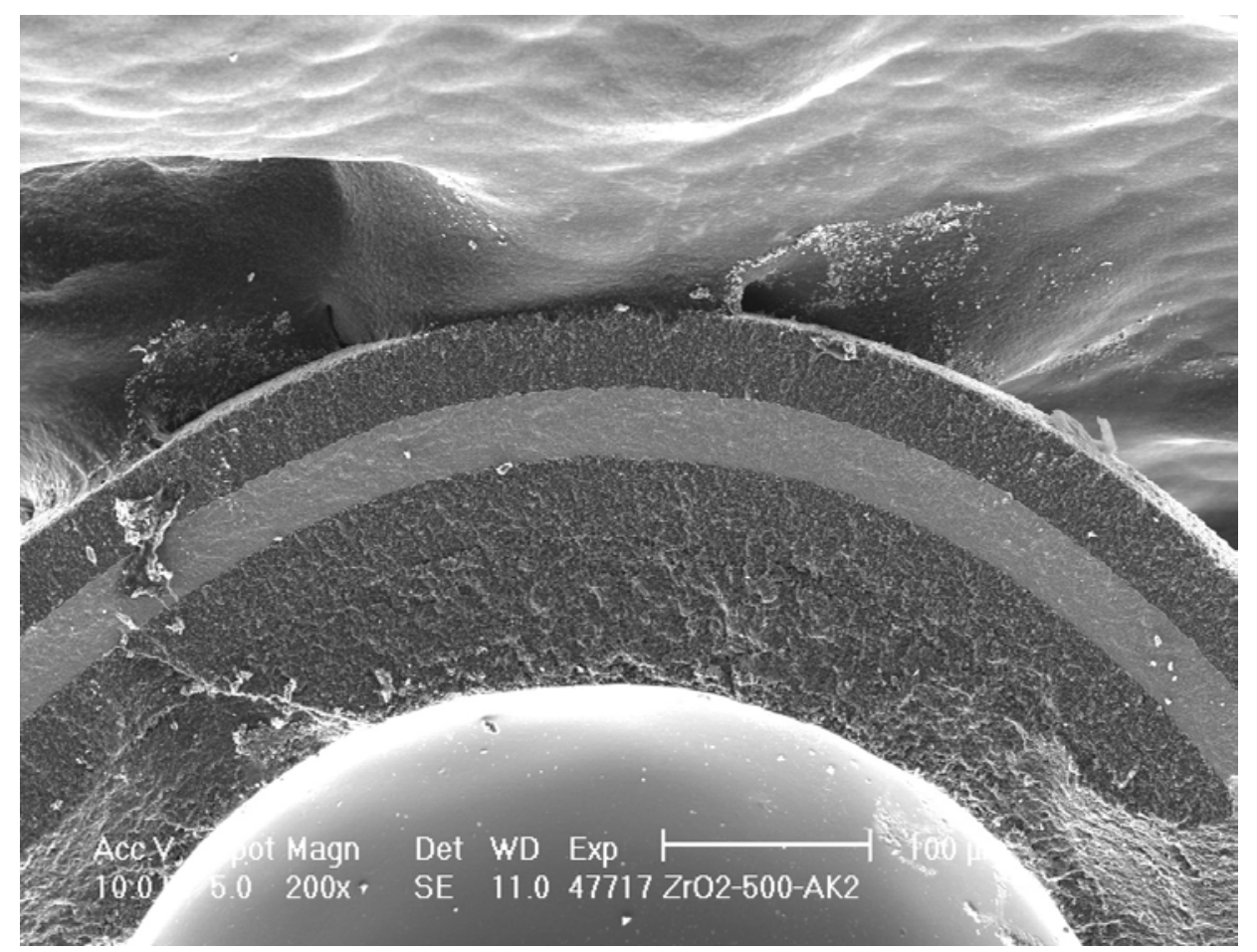

Figure 2-1: Fracture surface of $\mathrm{ZrO} 2-500-\mathrm{AK} 2$ showing buffer, IPyC, SiC, and OPyC. (SEM, secondary electron mode) 
ORNL/CF-05/12

Revision 1

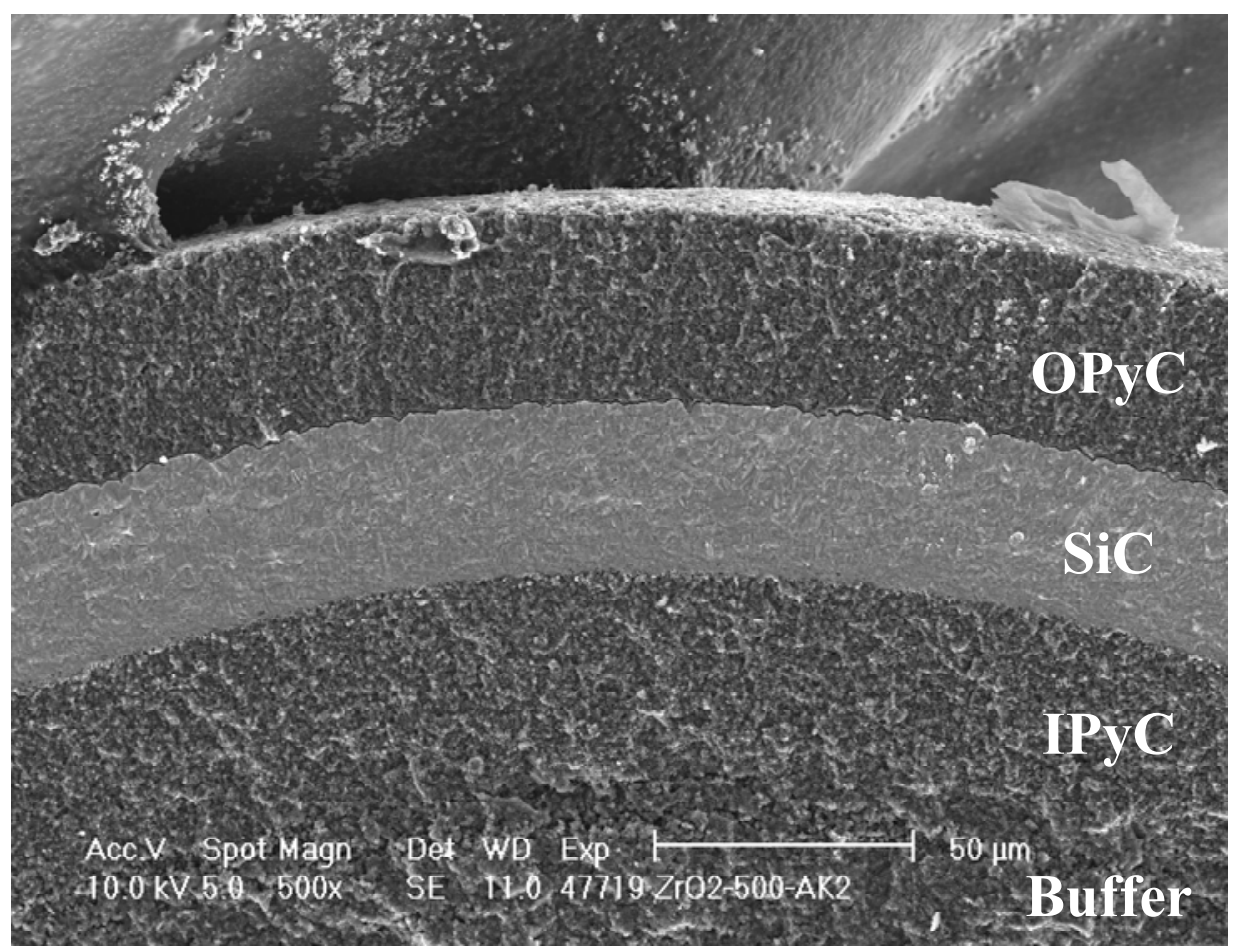

Figure 2-2: A comparison of fracture surfaces shows the high roughness of the buffer fracture surface (bottom) relative to the other fracture surfaces (SEM, secondary electron).

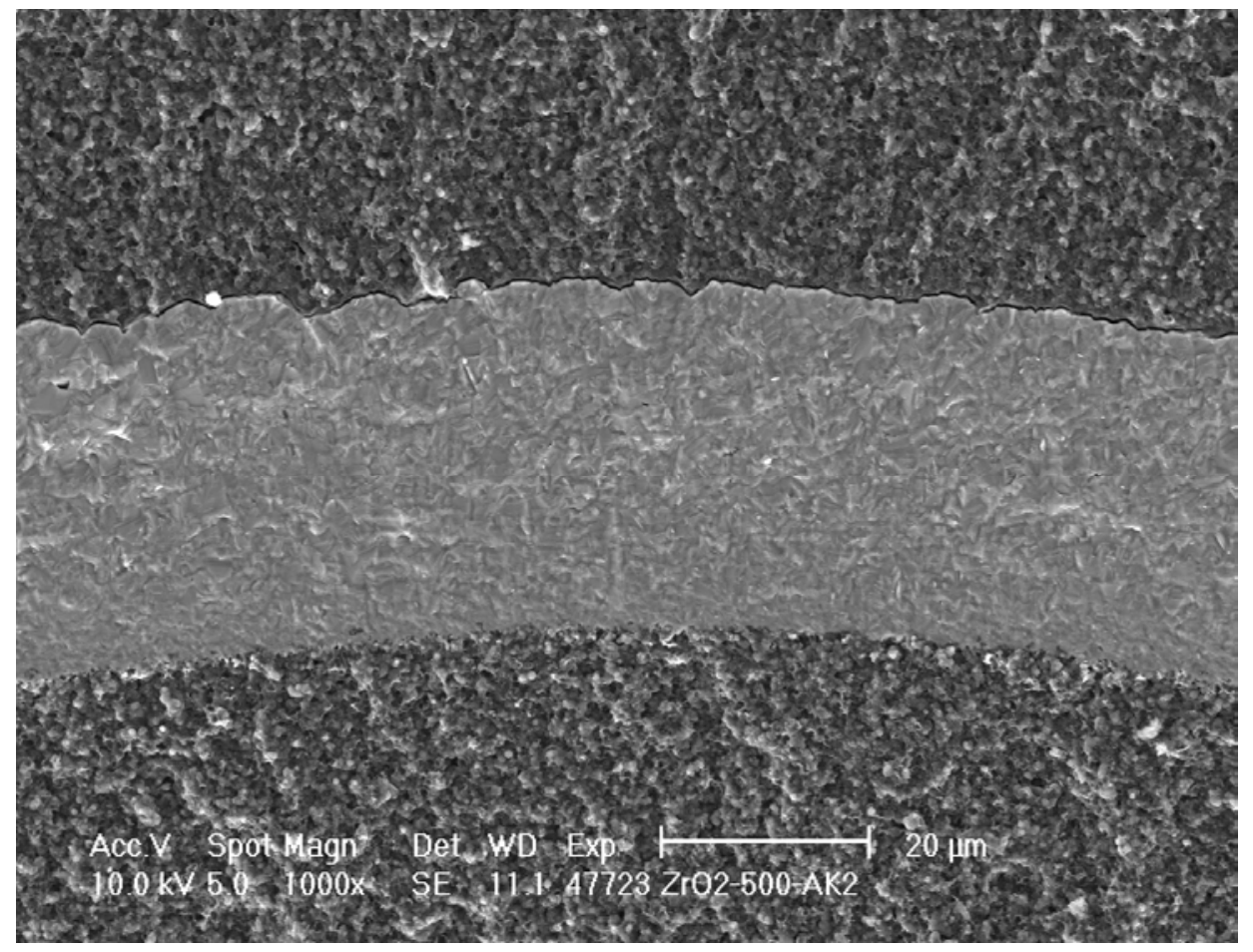

Figure 2-3: IPyC, SiC, and OPyC fracture surfaces (SEM, secondary electron). 
ORNL/CF-05/12

Revision 1

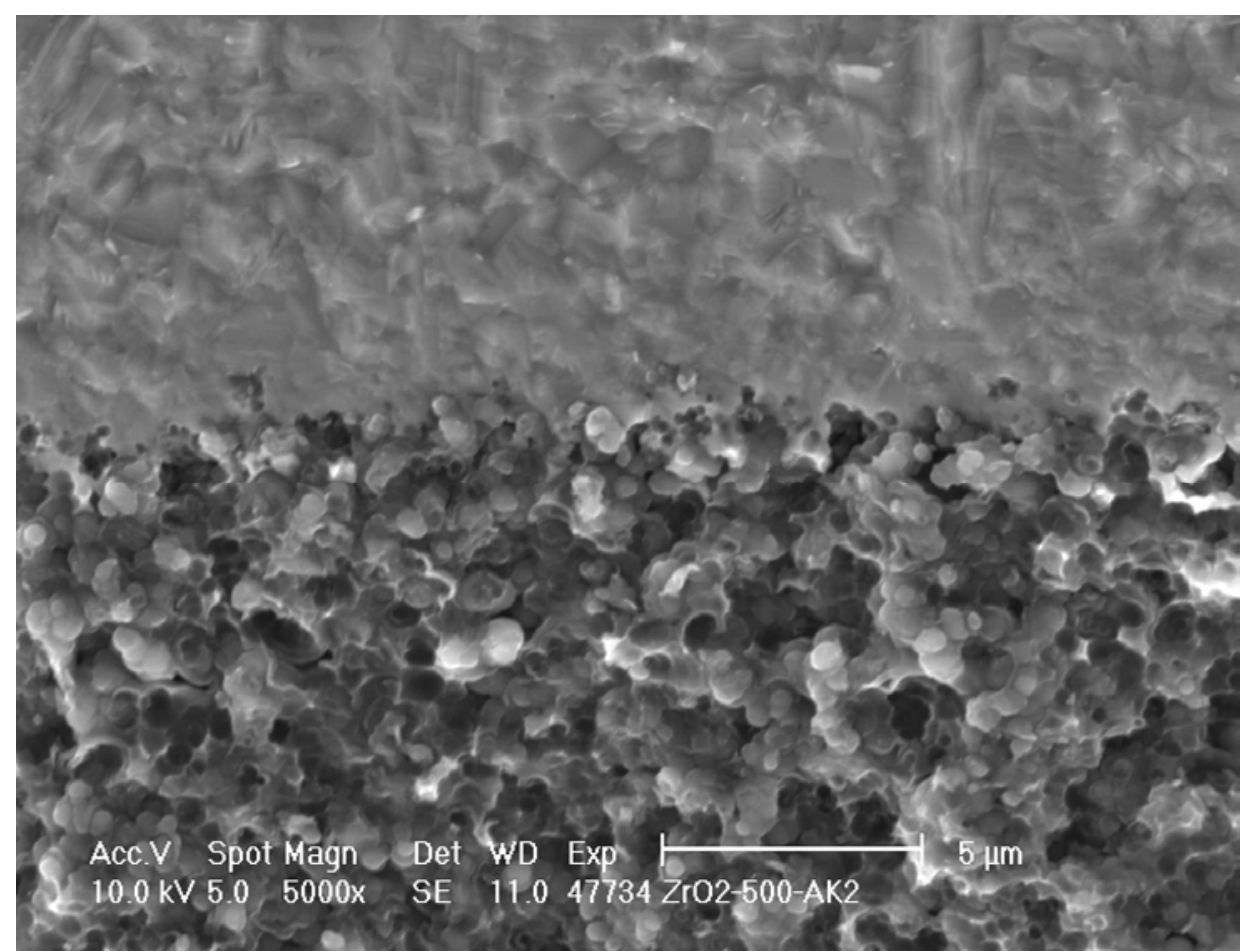

Figure 2-4: IPyC \& SiC fracture surfaces (SEM, secondary electron).

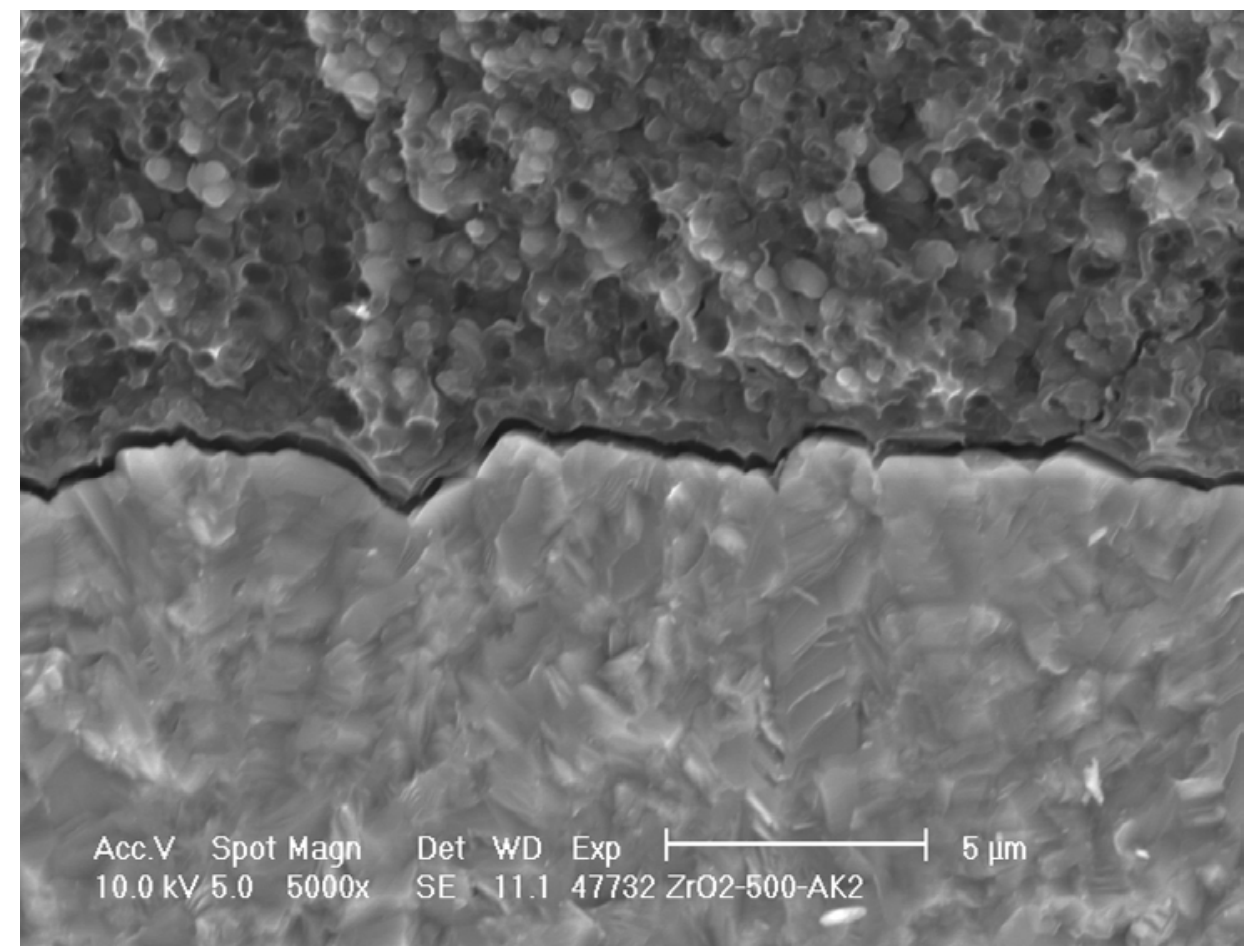

Figure 2-5: $\mathrm{SiC} \& \mathrm{OPyC}$ fracture surfaces (SEM, secondary electron) 
ORNL/CF-05/12

Revision 1

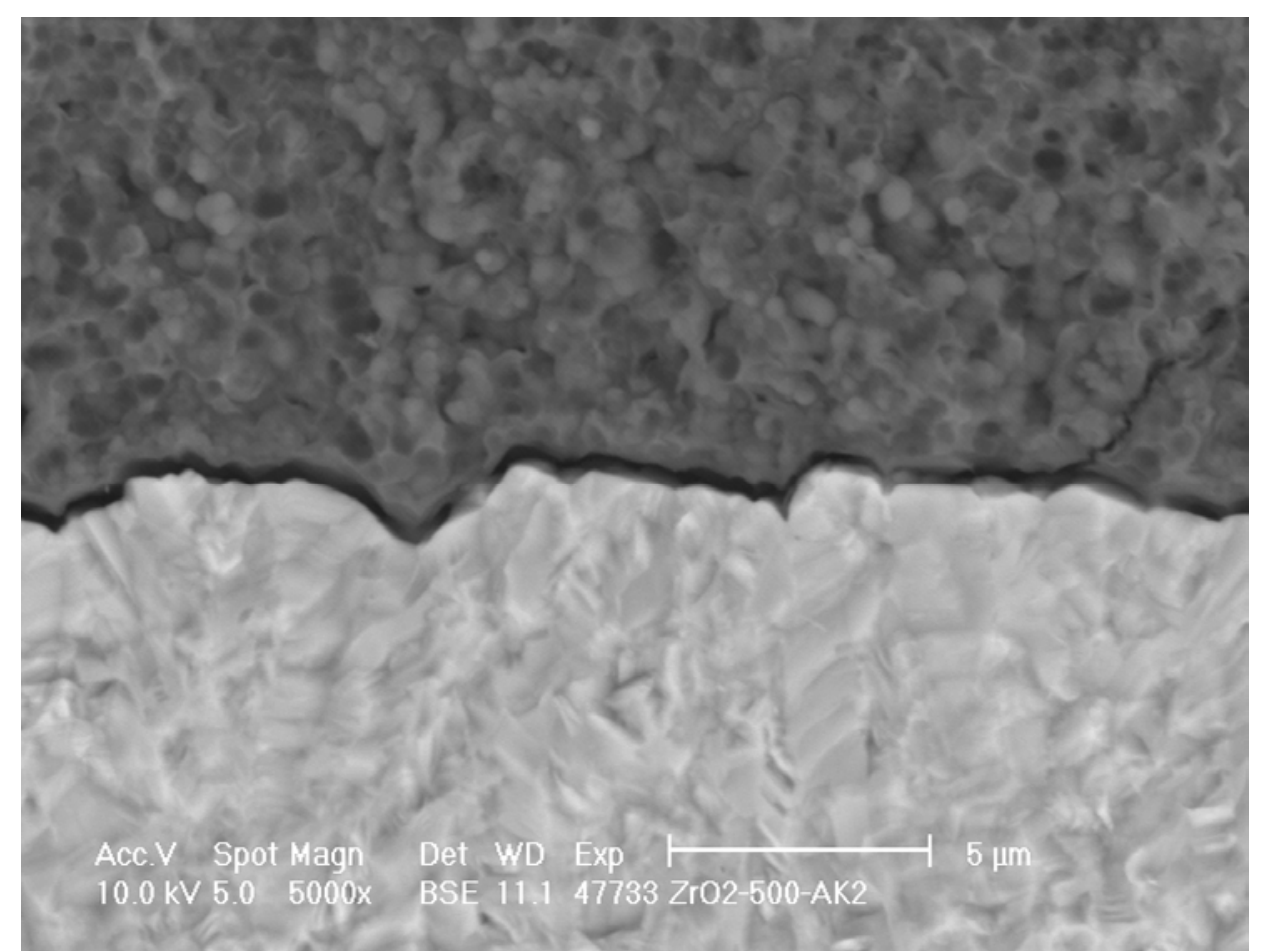

Figure 2-6: $\mathrm{SiC} \&$ OPyC fracture surfaces (SEM, backscatter electron mode).

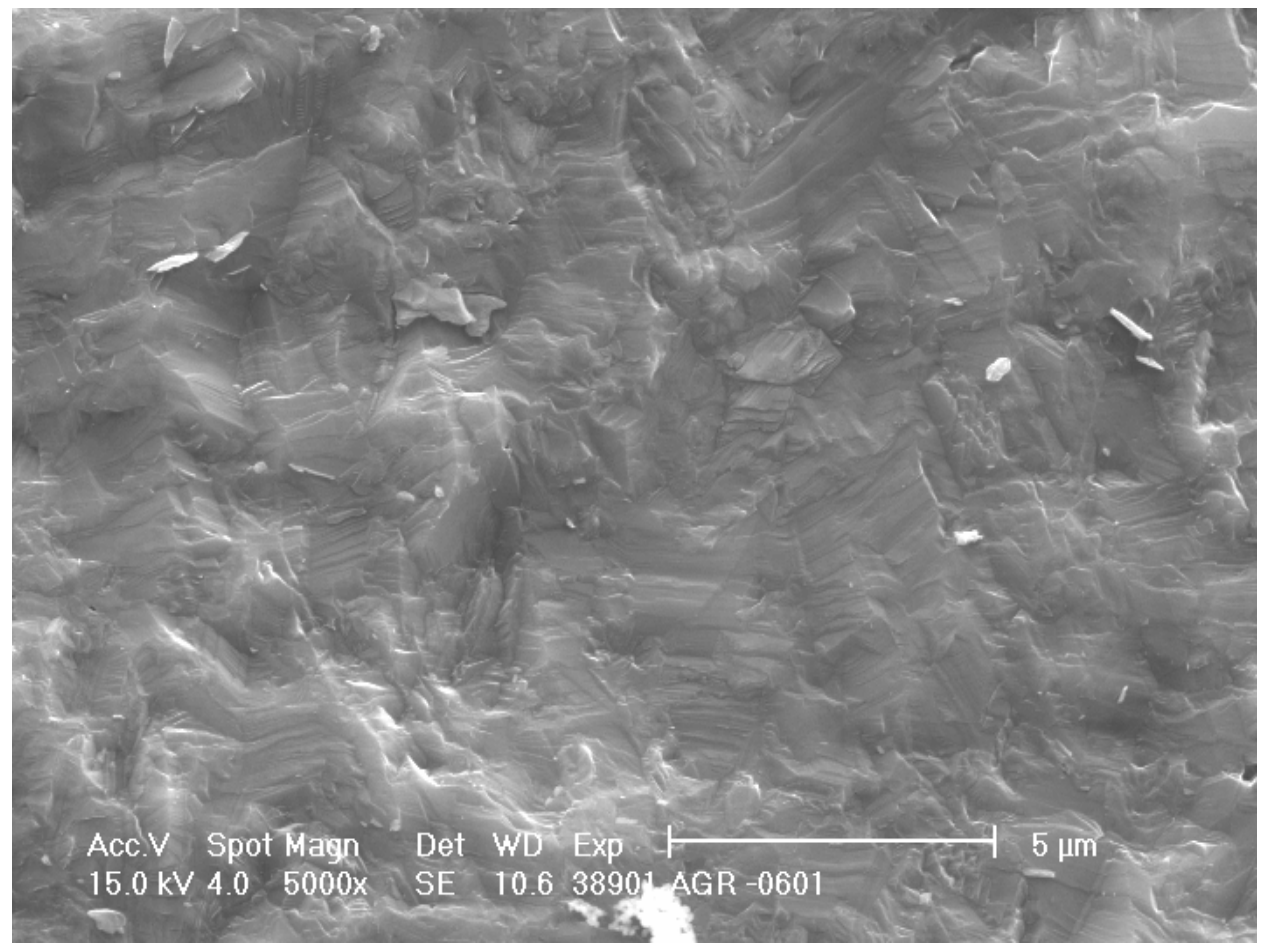

Figure 2-7: $\mathrm{SiC}$ fracture surface of German reference fuel (SEM, secondary electron) 


\title{
3 Measurement of Size and Shape Using Shadowgraphy
}

\author{
J.D. Hunn, A.K. Kercher, and J.R. Price
}

\subsection{Size and shape of kernels}

Size and shape measurements of the YSZ kernels by shadowgraphy has not been performed. Approximate measurements of kernel size were performed on cross sectioned samples. The data is reported in section 4.1 .

\subsection{Size and shape of coated particles}

Shadow images were obtained for a random orientation of 1368 coated particles sampled from $\mathrm{ZrO} 2-500-\mathrm{AK} 2$. Image analysis software was used to find the center of each kernel and identify 360 points around the perimeter. The uncertainty for this measurement was $\pm 1.1 \mu \mathrm{m}$. This data was then compiled to report aspect ratios (maximum radius/minimum radius), mean radius, standard deviation in radius, maximum radius, and minimum radius for each particle measured. The summary data from each particle in the sample was then compiled to obtain the average, standard deviation, maximum, and minimum of the individual particle quantities (aspect ratios, mean radius, standard deviation in radius, maximum radius, and minimum radius). Figure 3-1 contains the compiled data and shows the distributions of the radius aspect ratio and mean particle radius. The histogram labels correspond to the maximum value in that bin (top of bin). The same data was also computed in terms of diameter by measuring the distance between perimeter points that were separated by $180^{\circ}$. These values are summarized in Figure 3-2. The average and standard deviation of the mean diameter were exactly twice the values obtained for the mean radius. Thus, the statistical measurement for the size distribution was equivalent for the two methods. The radius aspect ratio is more sensitive to the faceting and non-symmetrical features than the diameter aspect ratio; as is observed, the average radius aspect ratio would be expected to be higher for typical TRISO particles. A higher average and standard deviation was observed for the radius aspect ratio than for the diameter aspect ratio.

The measured particles had an average mean radius of $454 \mu \mathrm{m}$ with a standard deviation in the distribution of $9 \mu \mathrm{m}$. Based on variable sampling statistics using a two-sided student's $\mathrm{t}$ distribution $(\mathrm{t}=1.96)$, the average mean radius of the $\mathrm{ZrO} 2-500-\mathrm{AK} 2$ particles was $453-455 \mu \mathrm{m}$ with $95 \%$ confidence. The largest particle measured had a mean radius of $494 \mu \mathrm{m}$. The smallest particle had a mean radius of $421 \mu \mathrm{m}$. 
ORNL/CF-05/12

Revision 1

\begin{tabular}{l|ccccc} 
& $\begin{array}{c}\text { Radius Aspect } \\
\text { Ratio }\end{array}$ & Mean Radius & $\begin{array}{c}\text { St. Dev. In } \\
\text { Radius }\end{array}$ & Minimum Radius & Maximum Radius \\
\hline Average & 1.072 & 454 & 8 & 438 & 469 \\
Standard Deviation & 0.021 & 9 & 2 & 10 & 10 \\
Minimum & 1.027 & 421 & 3 & 406 & 434 \\
Maximum & 1.331 & 494 & 35 & 469 & 561
\end{tabular}

\begin{tabular}{|c|c|}
\hline Aspect Ratio (R) & Frequency \\
\hline 1 & 0 \\
\hline 1.01 & 0 \\
\hline 1.02 & 0 \\
\hline 1.03 & 1 \\
\hline 1.04 & 35 \\
\hline 1.05 & 124 \\
\hline 1.06 & 263 \\
\hline 1.07 & 279 \\
\hline 1.08 & 250 \\
\hline 1.09 & 193 \\
\hline 1.1 & 110 \\
\hline 1.11 & 57 \\
\hline 1.12 & 21 \\
\hline 1.13 & 20 \\
\hline 1.14 & 4 \\
\hline 1.15 & 4 \\
\hline 1.16 & 1 \\
\hline 1.17 & 2 \\
\hline 1.18 & 2 \\
\hline 1.19 & 1 \\
\hline More & 1 \\
\hline
\end{tabular}

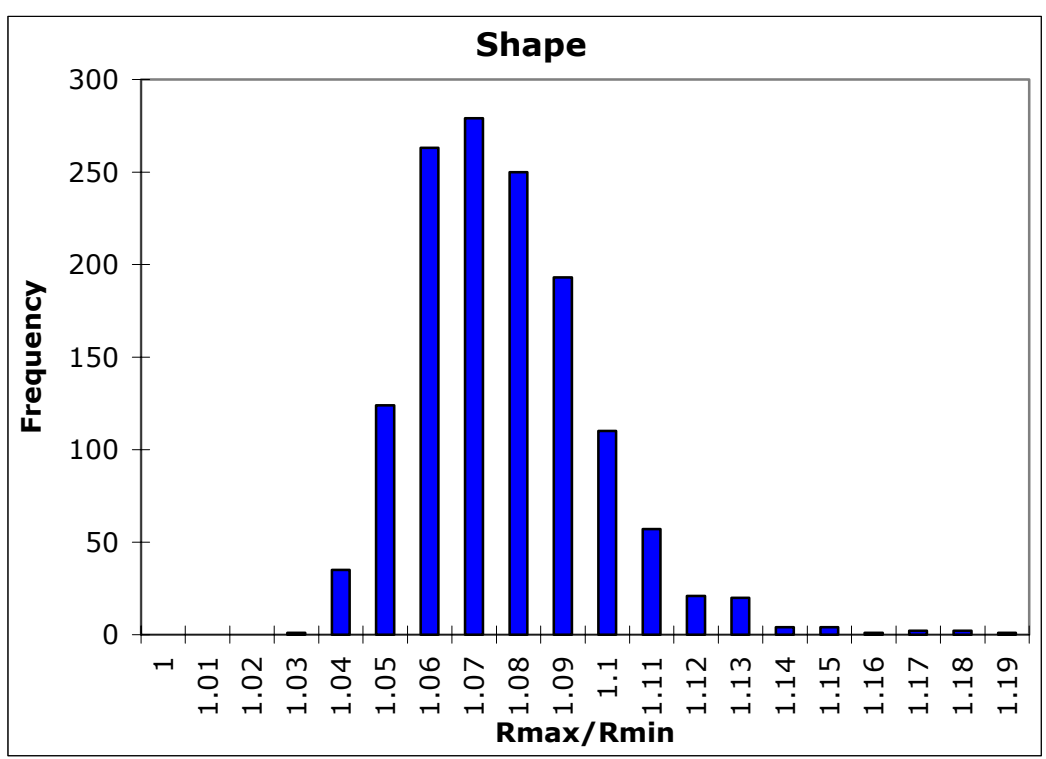

\begin{tabular}{rrr}
\hline \multicolumn{2}{c}{ Mean Radius } & Frequency \\
\hline & 425 & 1 \\
430 & 4 \\
435 & 8 \\
440 & 50 \\
& 445 & 124 \\
& 450 & 228 \\
& 455 & 332 \\
& 460 & 301 \\
& 465 & 164 \\
& 470 & 104 \\
& 475 & 32 \\
480 & 17 \\
& 485 & 1 \\
More & 490 & 1 \\
& 495 & 1 \\
& & 0 \\
\hline
\end{tabular}

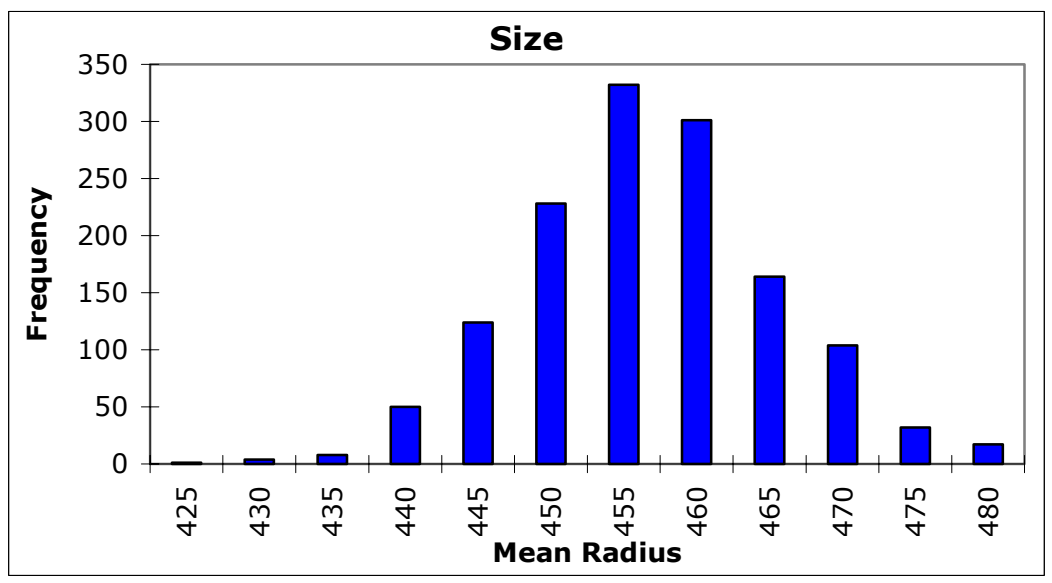

Figure 3-1: Size and shape summary for 1368 coated particles. Measurements are distance from best circle fit center to edge in $\mu \mathrm{m}$. 
ORNL/CF-05/12

Revision 1

\begin{tabular}{l|ccccc} 
& $\begin{array}{c}\text { Diameter Aspect } \\
\text { Ratio }\end{array}$ & Mean Diameter & $\begin{array}{c}\text { St. Dev. In } \\
\text { Diameter }\end{array}$ & Minimum Diameter & Maximum Diameter \\
\hline Average & 1.045 & 909 & 12 & 887 & 928 \\
Standard Deviation & 0.016 & 17 & 4 & 18 & 20 \\
Minimum & 1.011 & 843 & 3 & 823 & 856 \\
Maximum & 1.227 & 985 & 63 & 951 & 1089
\end{tabular}

\begin{tabular}{rr}
\hline Aspect Ratio $(D)$ & Frequency \\
\hline 1 & 0 \\
1.005 & 0 \\
1.01 & 0 \\
1.015 & 5 \\
1.02 & 23 \\
1.025 & 54 \\
1.03 & 119 \\
1.035 & 154 \\
1.04 & 186 \\
1.045 & 195 \\
1.05 & 182 \\
1.055 & 125 \\
1.06 & 112 \\
1.065 & 76 \\
1.07 & 51 \\
1.075 & 30 \\
1.08 & 21 \\
1.085 & 15 \\
1.09 & 9 \\
1.095 & 4 \\
1.1 & 1 \\
&
\end{tabular}

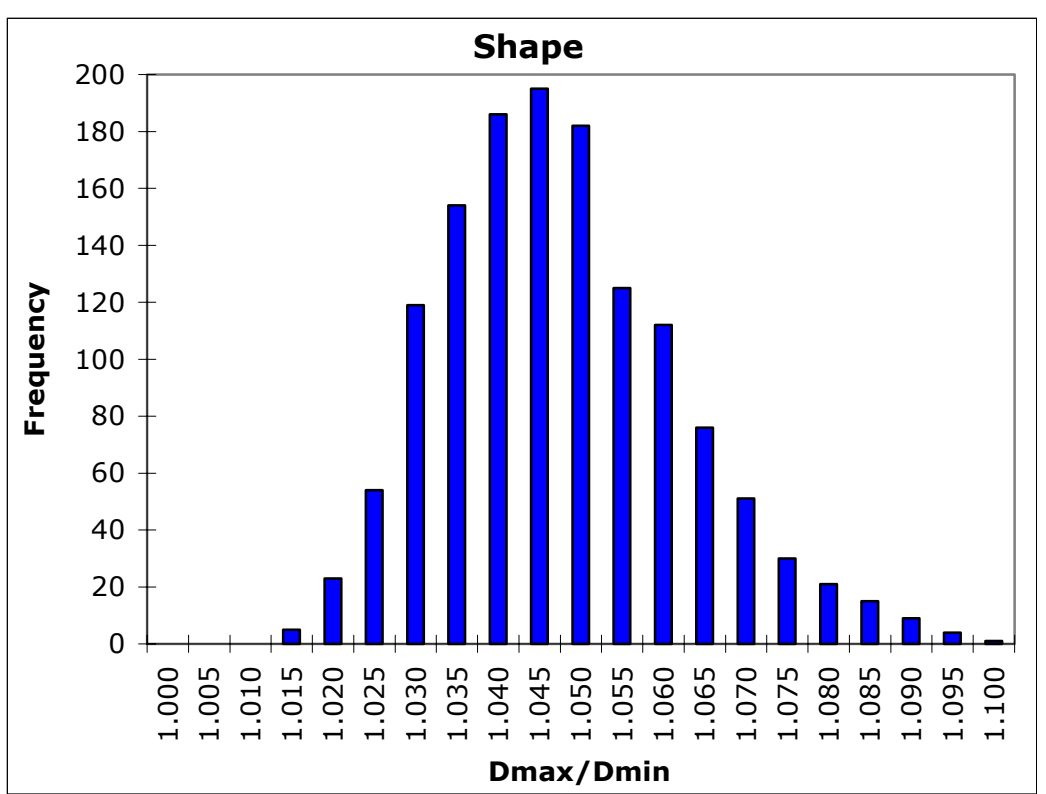

\begin{tabular}{|c|c|}
\hline Mean Diameter & Frequency \\
\hline 850 & 1 \\
\hline 860 & 3 \\
\hline 870 & 9 \\
\hline 880 & 53 \\
\hline 890 & 118 \\
\hline 900 & 230 \\
\hline 910 & 329 \\
\hline 920 & 299 \\
\hline 930 & 168 \\
\hline 940 & 109 \\
\hline 950 & 27 \\
\hline 960 & 18 \\
\hline 970 & 2 \\
\hline 980 & 1 \\
\hline 990 & 1 \\
\hline More & 0 \\
\hline
\end{tabular}

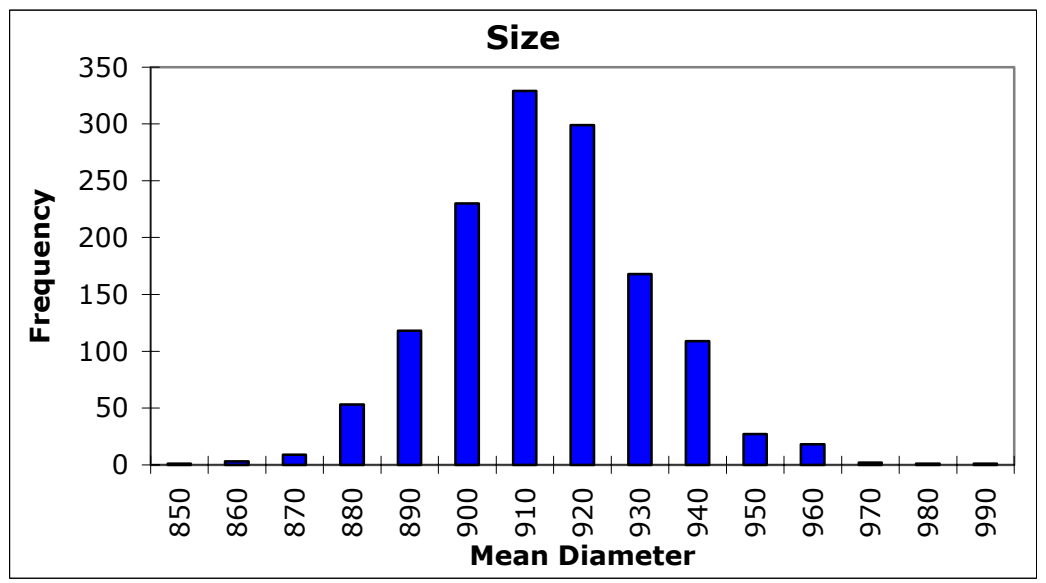

Figure 3-2: Size and shape summary for 1368 coated particles. Measurements are in $\mu \mathrm{m}$ from edge to edge through best circle fit center. 
A diameter aspect ratio is the conventional method for describing the shape of TRISO fuel particles. The average diameter aspect ratio was 1.045 (Figure 3-2). In the lot, the $99^{\text {th }}$ percentile for the diameter aspect ratio was between 1.08 and 1.11 to $95 \%$ confidence. The computer automated microscopy technique used by ORNL also readily provides the data to compute radius aspect ratios. The average radius aspect ratio $\left(\mathrm{R}_{\max } / \mathrm{R}_{\min }\right)$ was 1.072 (Figure 3-1). In the lot, the $99^{\text {th }}$ percentile for the radius aspect ratio was between 1.12 and 1.16 to $95 \%$ confidence. Faceting is the major source of asphericity in the $\mathrm{ZrO} 2-500-\mathrm{AK} 2$ particles (as is commonly seen in other TRISO particles). Because facets are defects that are radially asymmetric, particle faceting provides markedly different values for diameter aspect ratio and radius aspect ratio.

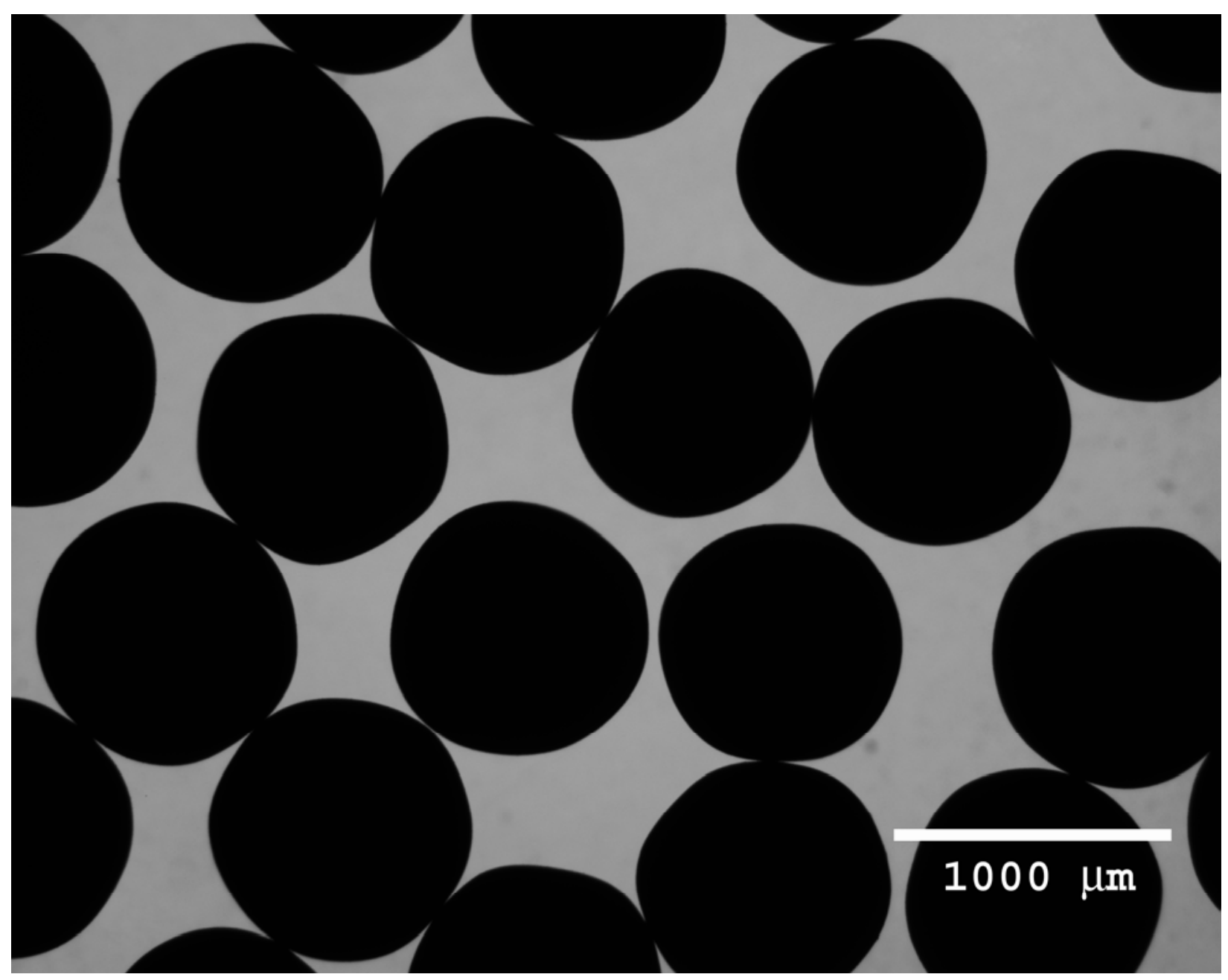

Figure 3-3: $\mathrm{ZrO} 2-500-\mathrm{AK} 2$ TRISO surrogate particles. 
ORNL/CF-05/12

Revision 1

\begin{tabular}{l|cc} 
& Radius Cmax & Cmax \\
\hline Average & 1.73 & 0.0037 \\
Standard Deviation & 0.25 & 0.0005 \\
Minimum & 1.30 & 0.0027 \\
Maximum & 3.14 & 0.0063
\end{tabular}

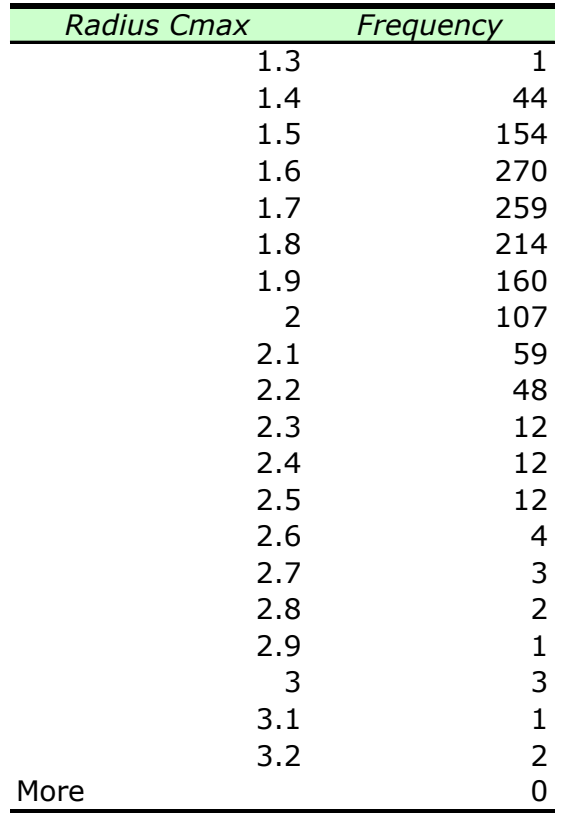

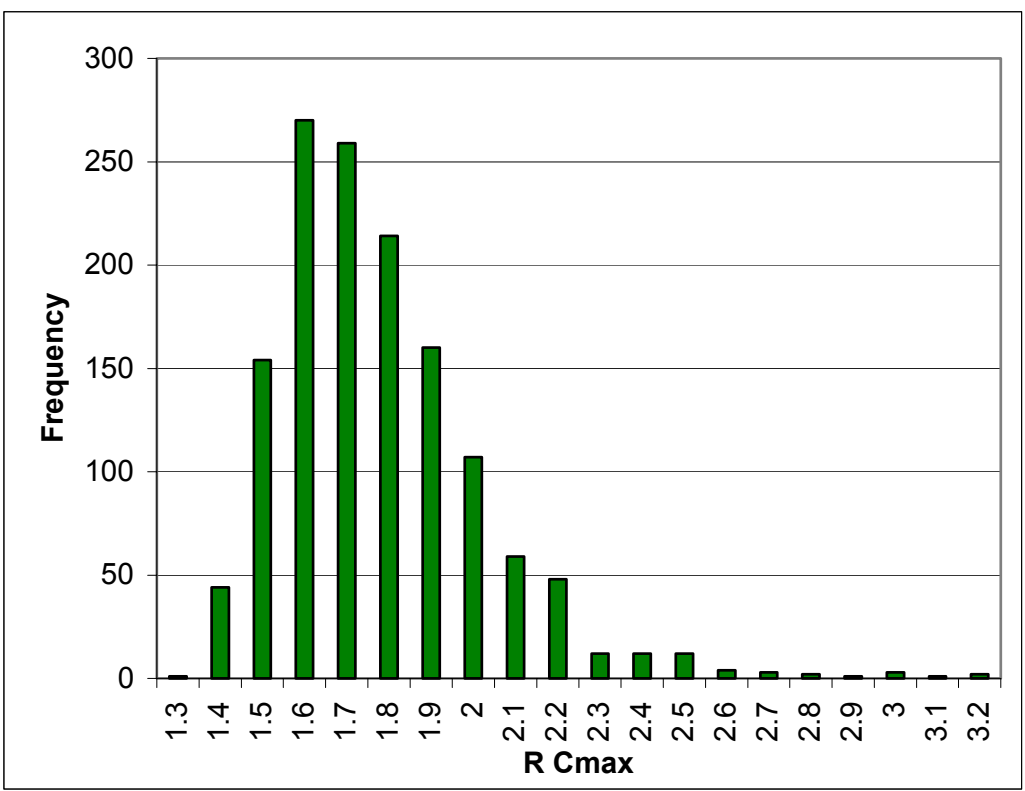

Figure 3-4: An alternate metric for shape, $\mathrm{RC}_{\max }$, has been developed at ORNL.

In TRISO fuel particles, the probability of layer fracture depends on the layer shape and consequently the particle shape. Computer models have correlated the probability of layer fracture to the sharpness of features on TRISO particles. Aspect ratios describe general particle shape and have not been strongly correlated to particle fracture mechanisms. At ORNL, a new metric has been developed that quantifies the sharpest observed feature on each individual particle and that has been correlated to layer fracture by membrane theory approximations. The new metric proposed by ORNL researchers is the product of the curvature and the radius at the point of maximum curvature $\left(\mathrm{RC}_{\max }\right)$. Curvature is computed in the FFT (fast Fourier transform) domain using ten harmonics based on the equation:

$$
C=\frac{x^{\prime} y^{\prime \prime}-y^{\prime} x^{\prime \prime}}{\left(x^{\prime 2}+y^{\prime 2}\right)^{3 / 2}}
$$

where $\mathrm{x}$ and $\mathrm{y}$ are the $\mathrm{x}$ and $\mathrm{y}$ coordinates of the point on the boundary (based on a FFT fit). The sharpest feature observed for a particle occurs at the point of maximum curvature, and the curvature $\left(\mathrm{C}_{\max }\right.$ given in $\left.\mu \mathrm{m}^{-1}\right)$ is multiplied by the local radius to make a unitless metric that is independent of particle size. While this recently devised metric is not currently used to qualify TRISO fuel, this information has been calculated for TRISO materials in the AGR program because of its potential future value in modeling fuel performance. Figure 3-4 contains a histogram of $\mathrm{RC}_{\max }$ for $\mathrm{ZrO} 2-500-\mathrm{AK} 2$ and associated data. The average value for $\mathrm{RC}_{\max }$ was 1.73. In the lot, the $99^{\text {th }}$ percentile for $\mathrm{RC}_{\max }$ was between 2.46 and 2.99 to $95 \%$ confidence. 


\title{
4 Measurement of Coating Thicknesses
}

\author{
J.D. Hunn, A.K. Kercher, and J.R. Price
}

Coating thicknesses were measured on 127 particles by mounting particles in a clear epoxy and grinding and polishing the particles to close to, but not beyond, the midpoint. The polished cross sections were imaged in bright field reflected mode with a computer-automated optical microscope and the images were computer analyzed to extract the thickness information for each layer. The deviation of the measured layer thickness from the actual layer thickness due to the polished cross section not being exactly at a midplane was corrected by measuring the outer diameter of the particle and applying a geometric correction. The outer diameter was measured by backlighting the clear epoxy mount to obtain a shadow image of the particle in addition to the bright field reflected image.

\subsection{Kernel diameter}

Kernel diameter and radius aspect ratio was determined by cross-section analysis. This is not the preferred method for determination of kernel size and shape, but unfortunately the original kernels were not imaged and no sample of those surrogate kernels is currently available. There is potentially a much larger uncertainty in determining size and shape of the kernels by crosssection when compared to using shadowgraphic methods. The deviation from midplane was corrected, as noted above, however, the associated error in this correction was greater than it was for the coatings due to the fact that the kernel edge was closer to the geometric center of the particle and to the fact that the kernels may have been off center in some cases.

Figure 4-1 shows the data summary for the kernel radius. The histogram labels correspond to the maximum value in that bin (top of bin). The average mean radius was $265 \mu \mathrm{m}$ with a standard deviation of $9 \mu \mathrm{m}$. The average $\mathrm{R}_{\max } / \mathrm{R}_{\min }$ was 1.02 . The aspect ratio was adjusted by a systematic offset error associated with extracting a ratio of a maximum value over a minimum value (which is based on pixel size and average kernel radius, as discussed in depth in ORNL/CF-04/07). Based on variable sampling statistics using a two-sided student's $t$ distribution $(\mathrm{t}=1.98)$, the average mean diameter of the YSZ kernels was $528-534 \mu \mathrm{m}$ with $95 \%$ confidence. The kernel manufacturer (Nikkato Corporation) supplied an inspection sheet for the kernel lot. According to the manufacturer, the average kernel diameter was $526.1 \mu \mathrm{m}$ with a standard deviation in the sample of $17.1 \mu \mathrm{m}$ for a sample size of 100 kernels. The reasonably close agreement with manufacturer data suggested that the measurement bias or measurement uncertainty caused by extracting kernel size from cross-sections was probably small. 
ORNL/CF-05/12

Revision 1

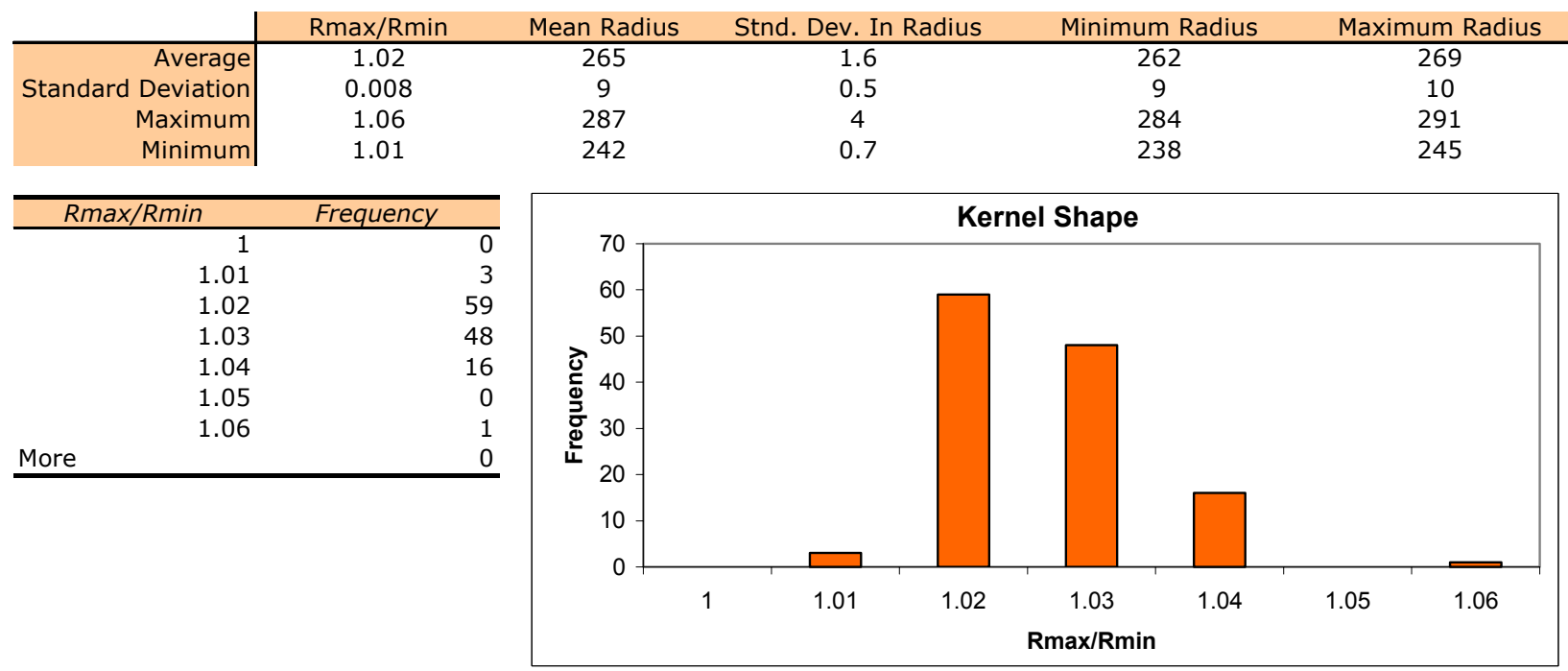

\begin{tabular}{rrr}
\hline \multicolumn{2}{c}{ Mean Radius } & Frequency \\
\hline & 245 & 2 \\
250 & 4 \\
255 & 10 \\
260 & 18 \\
265 & 27 \\
& 270 & 24 \\
& 275 & 25 \\
& 280 & 8 \\
& 285 & 6 \\
More & 290 & 3 \\
\hline
\end{tabular}

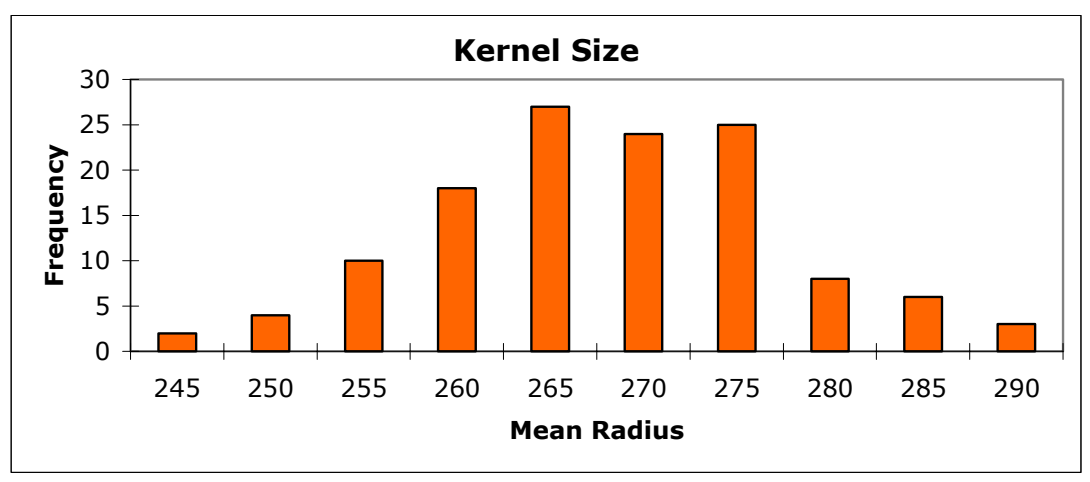

Figure 4-1: Data summary for kernel radius from cross section measurement. Radii are in $\mu \mathrm{m}$.

\subsection{Buffer thickness}

Figure 4-2 shows the data summary for the measurements made on the buffer. The average mean buffer thickness was $85 \mu \mathrm{m}$ with a standard deviation in the distribution of $7 \mu \mathrm{m}$. Based on variable sampling statistics using a two-sided student's $t$ distribution $(t=1.98)$, the average mean thickness of the buffer in this lot of particles was $84-86 \mu \mathrm{m}$ with $95 \%$ confidence. The thickest buffer layer was $105 \mu \mathrm{m}$ (average). The thinnest buffer layer was $71 \mu \mathrm{m}$ (average). 
ORNL/CF-05/12

Revision 1

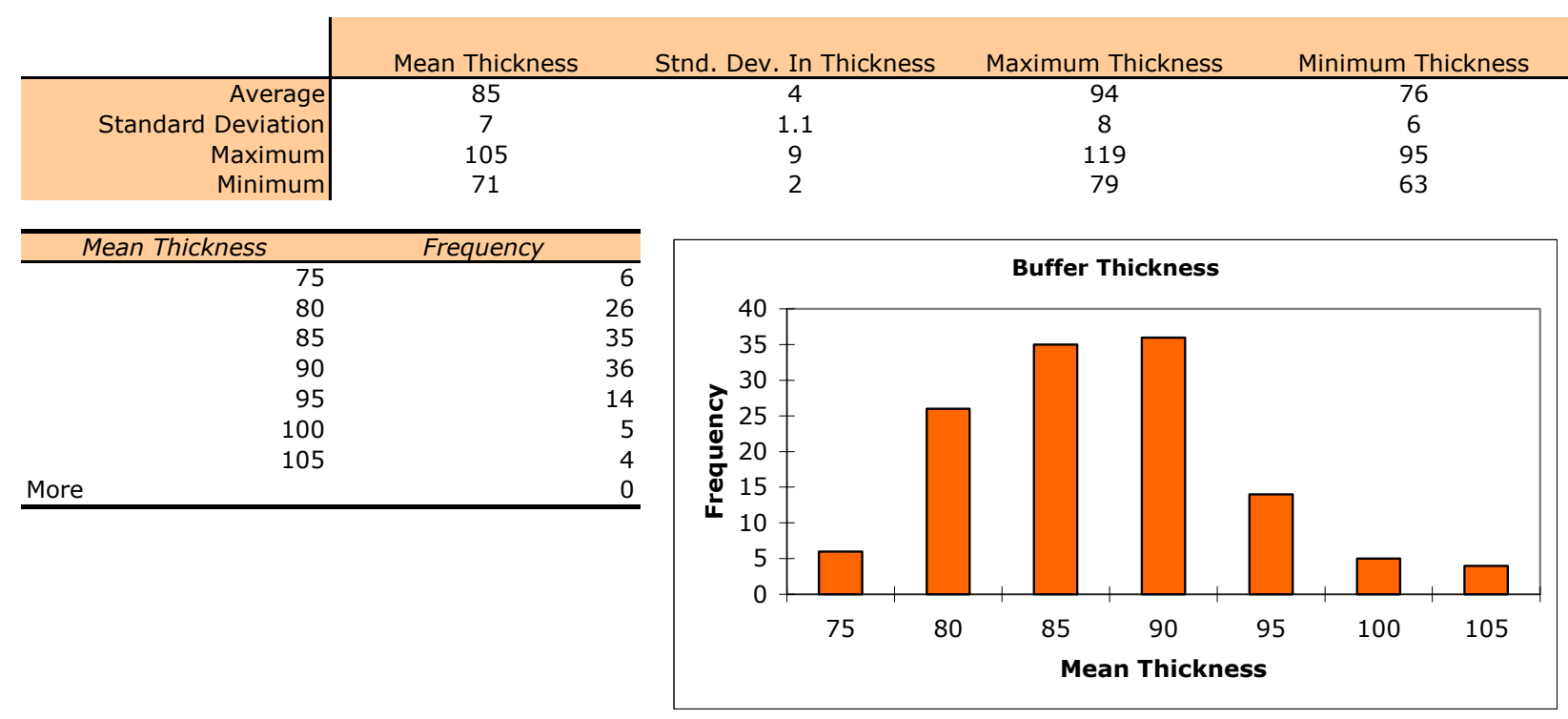

Figure 4-2: Data summary for buffer thickness. Thicknesses are in $\mu \mathrm{m}$.

\subsection{IPyC thickness}

Figure 4-3 shows the data summary for the measurements made on the IPyC. The average mean IPyC thickness was $41 \mu \mathrm{m}$ with a standard deviation in the distribution of $2 \mu \mathrm{m}$. Based on variable sampling statistics using a two-sided student's $t$ distribution $(\mathrm{t}=1.98)$, the average mean IPyC thickness of the ZrO2-500-AK2 particles was 40-42 $\mu \mathrm{m}$ with $95 \%$ confidence. The thickest IPyC layer was $50 \mu \mathrm{m}$ (average). The thinnest IPyC layer was $36 \mu \mathrm{m}$ (average).

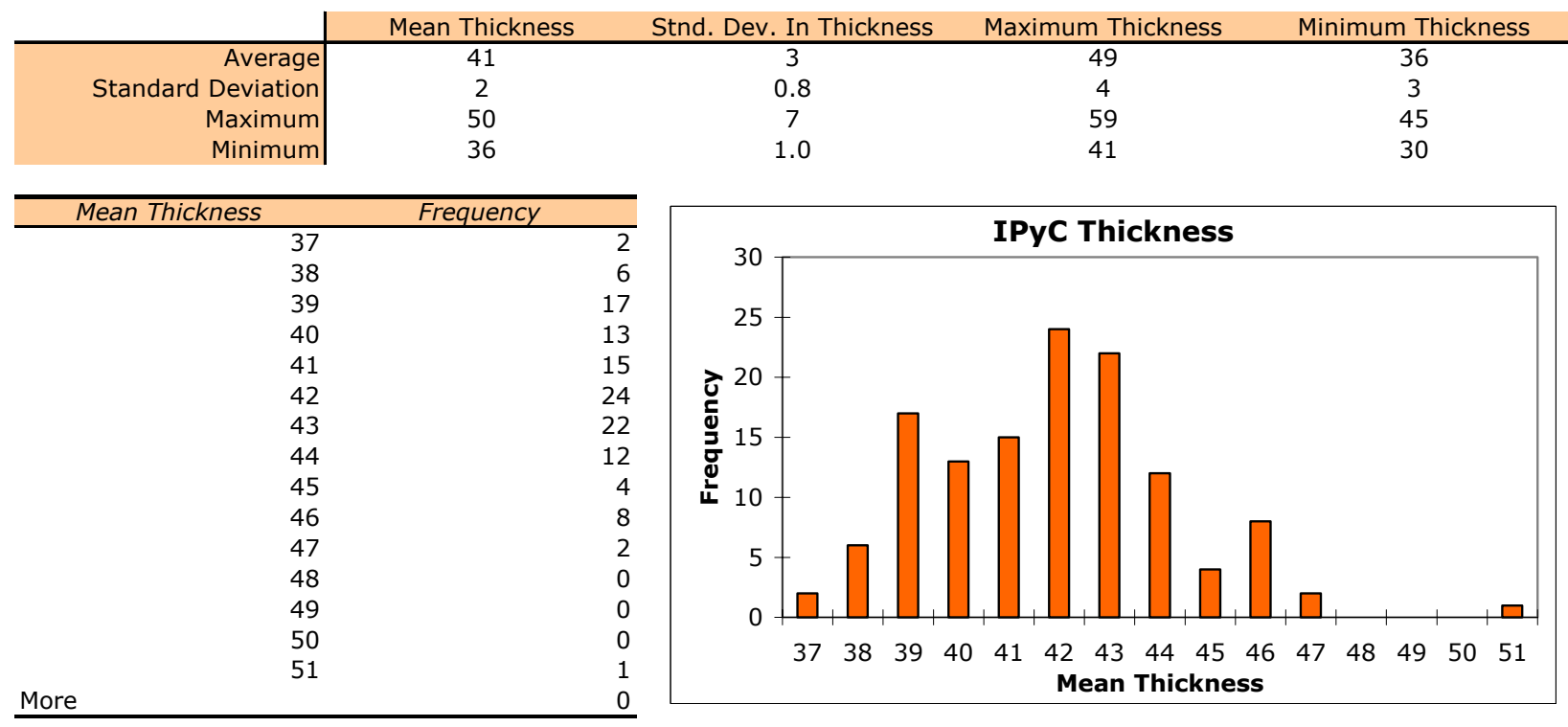

Figure 4-3: Data summary for IPyC thickness. Thicknesses are in $\mu \mathrm{m}$. 


\subsection{SiC thickness}

Figure 4-4 shows the data summary for the measurements made on the SiC. The average mean SiC thickness was $31 \mu \mathrm{m}$ with a standard deviation in the distribution of $1.0 \mu \mathrm{m}$. Based on variable sampling statistics using a two-sided student's $t$ distribution $(\mathrm{t}=1.98)$, the average mean $\mathrm{SiC}$ thickness of the $\mathrm{ZrO} 2-500-\mathrm{AK} 2$ particles was $30-32 \mu \mathrm{m}$ with $95 \%$ confidence. The thickest $\mathrm{SiC}$ layer was $33 \mu \mathrm{m}$ (average). The thinnest $\mathrm{SiC}$ layer was $27 \mu \mathrm{m}$ (average).

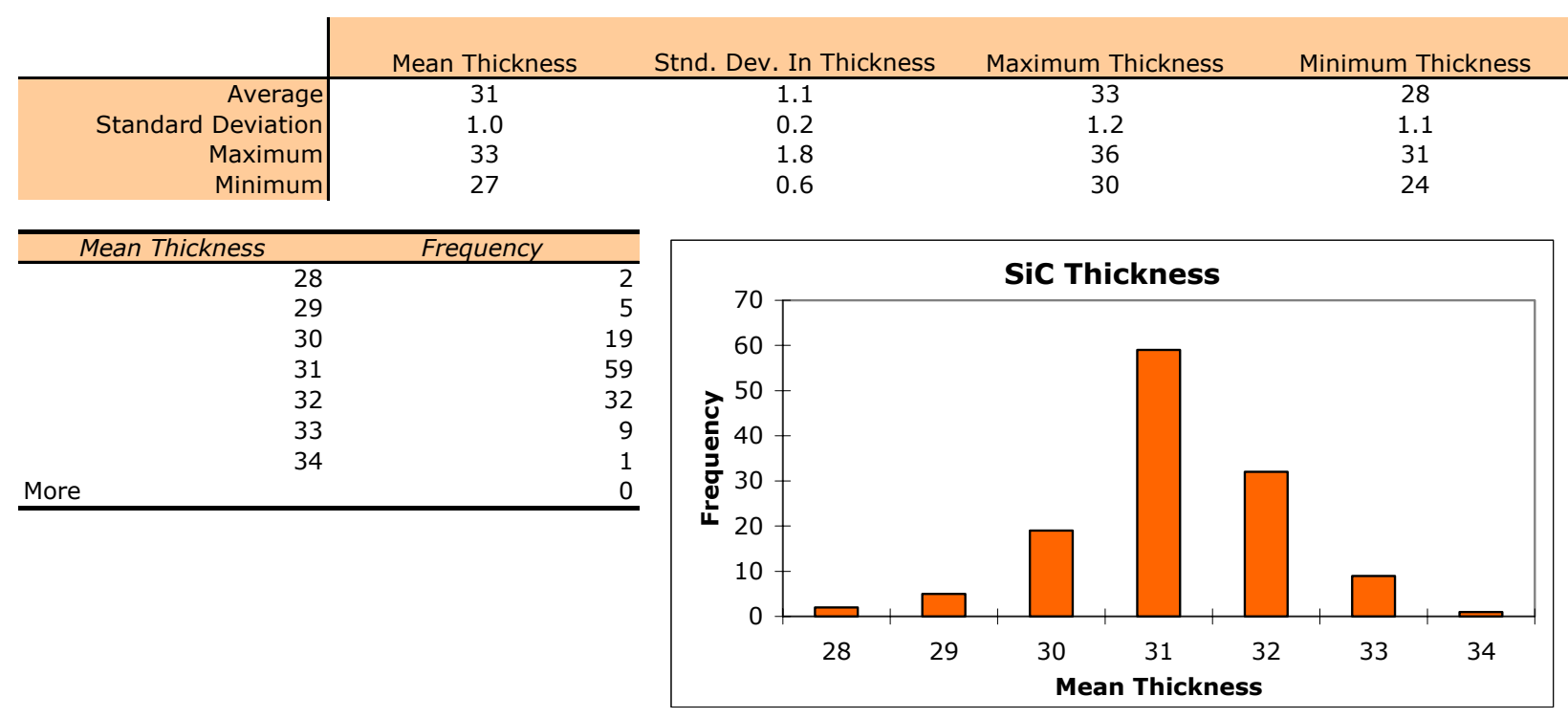

Figure 4-4: Data summary for $\mathrm{SiC}$ thickness. Thicknesses are in $\mu \mathrm{m}$.

\subsection{OPyC thickness}

Figure 4-5 shows the data summary for the measurements made on the OPyC. The average mean OPyC thickness was $36 \mu \mathrm{m}$ with a standard deviation in the distribution of $1.6 \mu \mathrm{m}$. Based on variable sampling statistics using a two-sided student's $t$ distribution $(t=1.98)$, the average mean OPyC thickness of the $\mathrm{ZrO} 2-500-\mathrm{AK} 2$ particles was $35-37 \mu \mathrm{m}$ with $95 \%$ confidence. The thickest OPyC layer was $40 \mu \mathrm{m}$ (average). The thinnest OPyC layer was $31 \mu \mathrm{m}$ (average). 
ORNL/CF-05/12

Revision 1

\begin{tabular}{|c|c|c|}
\hline & \multicolumn{2}{|l|}{ Mean Thickness } \\
\hline Average & 36 & \\
\hline Standard Deviation & 1.6 & \\
\hline Maximum & 40 & \\
\hline Minimum & 31 & \\
\hline Mean Thickness & Frequency & \\
\hline 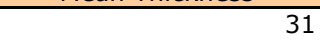 & & $\overline{1}$ \\
\hline 32 & & 2 \\
\hline 33 & & 1 \\
\hline 34 & & 7 \\
\hline 35 & & 8 \\
\hline 36 & & 31 \\
\hline 37 & & 35 \\
\hline 38 & & 27 \\
\hline 39 & & 9 \\
\hline 40 & & 5 \\
\hline 41 & & 1 \\
\hline More & & 0 \\
\hline
\end{tabular}

Stnd. Dev. In Thickness Maximum Thickness Minimum Thickness

$\begin{array}{ccc}1.7 & 40 & 33 \\ 0.4 & 2 & 1.8 \\ 3 & 47 & 37 \\ 0.9 & 34 & 28\end{array}$

1.8
37

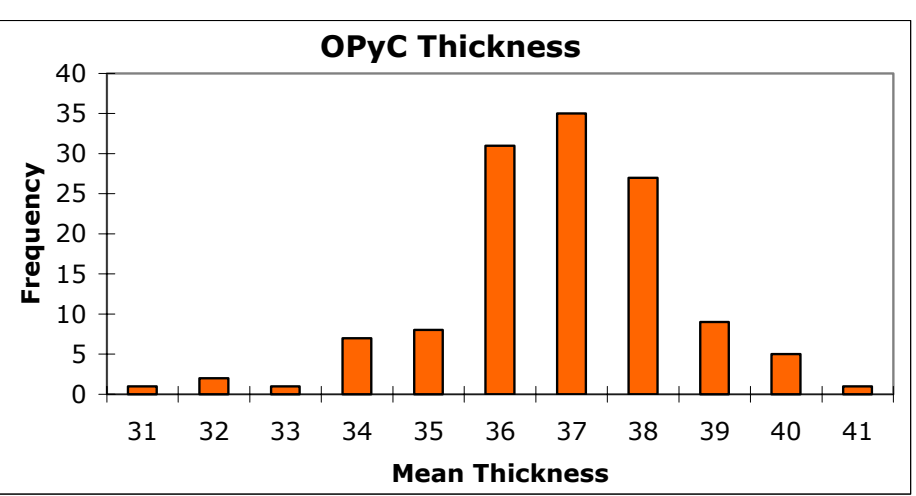

Figure 4-5: Data summary for OPyC thickness. Thicknesses are in $\mu \mathrm{m}$.

\subsection{Total particle radius}

The mean kernel radius and mean layer thickness data were summed for each particle as a comparison check against the data obtained from the whole particle shadowgraphy measurements made in section 3.2. The average mean radius obtained by summing the data from the cross section measurements was $459 \mu \mathrm{m}$ with a standard deviation in the distribution of $8 \mu \mathrm{m}$ (Figure 4-6). This agreed fairly well with the data obtained by shadow imaging the whole particles summarized in Figure 3-1 $(454 \pm 9 \mu \mathrm{m})$, especially considering the difficulties in measurement associated with the very odd shapes of the particles. The average radius aspect ratio (1.069) was nearly the same as measured by shadowgraphy (1.072). 
ORNL/CF-05/12

Revision 1

\begin{tabular}{rrr} 
& \multicolumn{2}{|c}{ Rmax/Rmin } \\
\hline Average & 1.07 & \\
Standard Deviation & 0.02 & \\
Maximum & 1.15 & \\
Minimum & 1.03 & \\
\hline Rmax/Rmin & & Frequency \\
\hline 1.04 & & 7 \\
1.05 & & 6 \\
1.06 & & 33 \\
1.07 & & 30 \\
1.08 & & 19 \\
1.09 & & 16 \\
1.1 & & 10 \\
1.11 & & 0 \\
1.12 & & 3 \\
1.13 & & 0 \\
1.14 & & 1 \\
1.15 & & 1 \\
More & & 0 \\
\hline
\end{tabular}

Mean Radius

459

8

487

441

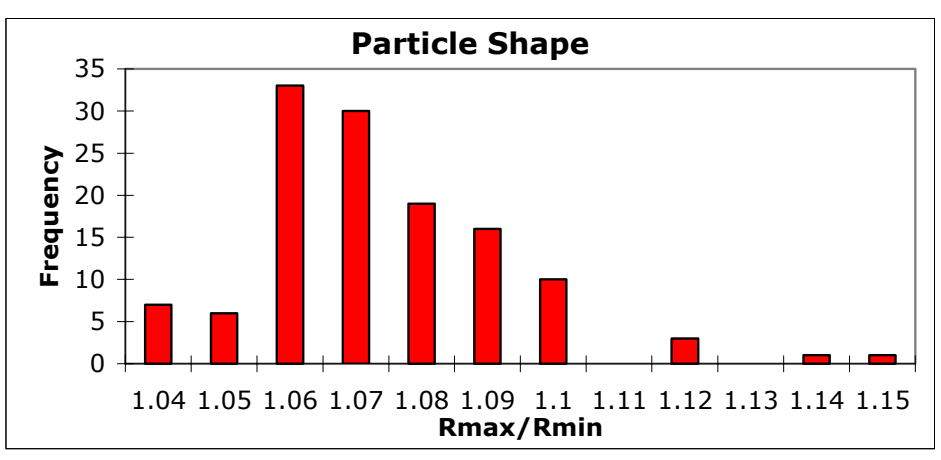

\begin{tabular}{lrr}
\hline Mean Radius & & Frequency \\
\hline & 445 & \\
& 450 & \\
& 455 & 16 \\
& 460 & 14 \\
& 465 & 38 \\
& 470 & 32 \\
& 475 & 15 \\
More & 480 & 6 \\
& 485 & 0 \\
& 490 & 0 \\
& & 1 \\
\end{tabular}

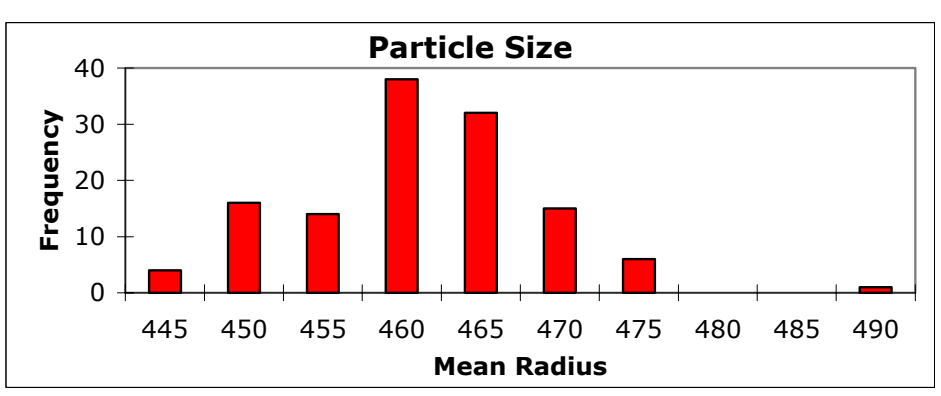

Figure 4-6: Data summary for total particle radius and radius aspect ratio from cross-section analysis. Total particle radius calculated from sum of kernel radius and layer thicknesses. Radii are in $\mu \mathrm{m}$. 


\title{
5 Density Measurement
}

\author{
D.L. Barker and J.D. Hunn
}

\subsection{SiC density}

The particle coatings were broken away from the kernel by placing several particles at a time into a stainless steel cylindrical dye and applying light pressure with a stainless steel cylindrical ram. Pieces of $\mathrm{IPyC} / \mathrm{SiC}$ fragments were removed and heated in air at $750^{\circ} \mathrm{C}$ for 90 min to remove the carbon layers. The separated $\mathrm{SiC}$ fragments were placed in a liquid gradient density column spanning a range of 3.15-3.21 g/cc. The column was created using an appropriate combination of methylene iodide and bromoform in such a way as to create a linear density gradient. Six calibration floats were used to generate a density versus position linear fit for the column and the density of the $\mathrm{SiC}$ fragments was calculated after measuring their equilibrium position in the column. Figure 5-1 shows the column calibration and measured values for $14 \mathrm{SiC}$ fragments. The average density measured by this method was $3.2048 \mathrm{~g} / \mathrm{cc}$ (standard deviation of the sample $=0.0015$; standard error of the mean $=0.0004)$. The $95 \%$ confidence interval for the average SiC density by this method was 3.204-3.206 g/cc. The density measured by this technique is expected to have a value between the envelope density and the skeletal density, depending on the porosity of the material and the extent to which the liquid penetrates the open pores. The SiC had very little porosity, so there should be little difference between the envelope density and the skeletal density. 
Calibrated Floats

\begin{tabular}{|c|c|c|c|}
\hline Density & $\begin{array}{c}\text { Top of } \\
\text { Float }\end{array}$ & $\begin{array}{c}\text { Bottom of } \\
\text { Float }\end{array}$ & $\begin{array}{c}\text { Float } \\
\text { Position }\end{array}$ \\
\hline & & & \\
\hline 3.150 & 73.64 & 97.20 & 85.42 \\
\hline 3.170 & 183.84 & 207.21 & 195.53 \\
\hline 3.190 & 313.81 & 335.94 & 324.88 \\
\hline 3.200 & 384.95 & 404.36 & 394.66 \\
\hline 3.210 & 457.91 & 481.46 & 469.69 \\
\hline
\end{tabular}

\begin{tabular}{|c|c|c|}
\hline $\begin{array}{c}\text { Particle } \\
\text { Number }\end{array}$ & $\begin{array}{c}\text { Particle } \\
\text { Position }\end{array}$ & $\begin{array}{c}\text { Calculated } \\
\text { Density }\end{array}$ \\
\hline 1 & & \\
\hline 2 & 415.54 & 3.203 \\
\hline 3 & 420.94 & 3.203 \\
\hline 4 & 425.75 & 3.205 \\
\hline 5 & 428.04 & 3.205 \\
\hline 6 & 430.99 & 3.205 \\
\hline 7 & 434.06 & 3.206 \\
\hline 8 & 436.07 & 3.206 \\
\hline 9 & 438.02 & 3.206 \\
\hline 10 & 440.62 & 3.207 \\
\hline 11 & 449.54 & 3.208 \\
\hline 12 & 438.26 & 3.206 \\
\hline 13 & 432.43 & 3.206 \\
\hline 14 & 441.13 & 3.207 \\
\hline & & \\
\hline
\end{tabular}

\begin{tabular}{|l|l|}
\hline Average & 3.205 \\
Standard Deviation & 0.001 \\
\hline
\end{tabular}

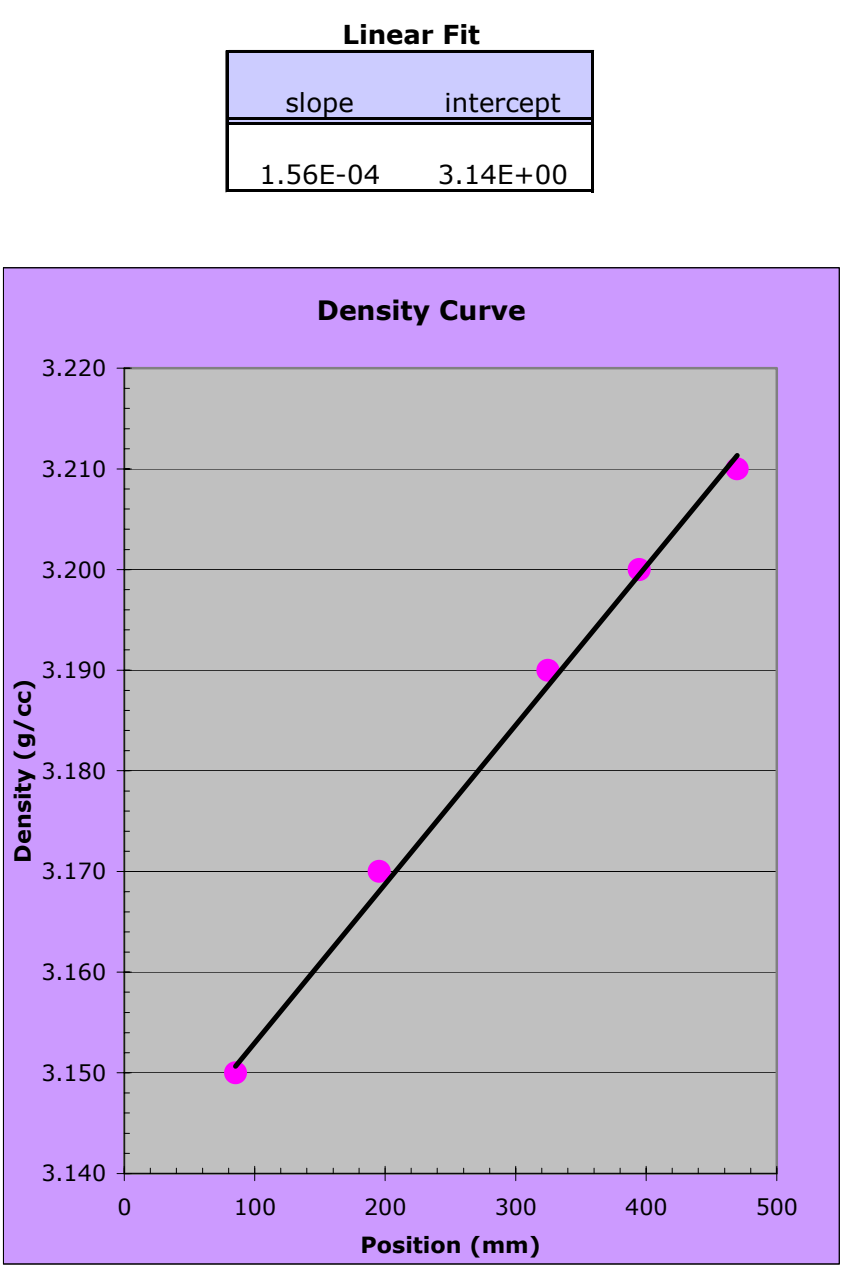

Figure 5-1: Density column data report for SiC. Densities are in $\mathrm{g} / \mathrm{cc}$.

\subsection{OPyC density}

Coatings were broken off of the particles as described in section 5.1. Pieces of free OPyC fragments were removed. The separated $\mathrm{OPyC}$ fragments were placed in a liquid gradient density column spanning a range of 1.7-2.1 g/cc. The column was created using an appropriate combination of ethylene bromide and tetrachloroethylene in such a way as to create a linear density gradient. Four calibration floats were used to generate a density versus position linear fit for the column that spanned the range of the unknown. The density of the OPyC fragments was calculated after measuring their equilibrium position in the column. Figure 5-2 shows the column calibration and measured values for the OPyC fragments. The average density measured by this method was $2.0119 \mathrm{~g} / \mathrm{cc}$ (standard deviation of the sample $=0.0018$; standard error of the mean $=0.0005)$. The $95 \%$ confidence interval for the average OPyC density by this method was $2.011-$ $2.013 \mathrm{~g} / \mathrm{cc}$. 
Calibrated Floats

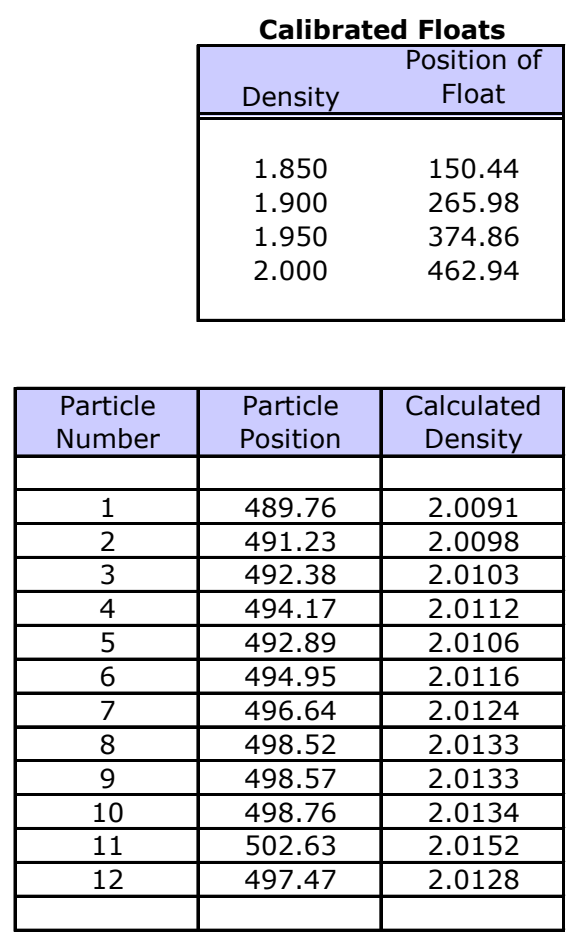

Average Density Standard Deviation

\begin{tabular}{|l|l|}
\hline 2.012 \\
\hline & 0.002 \\
\hline
\end{tabular}

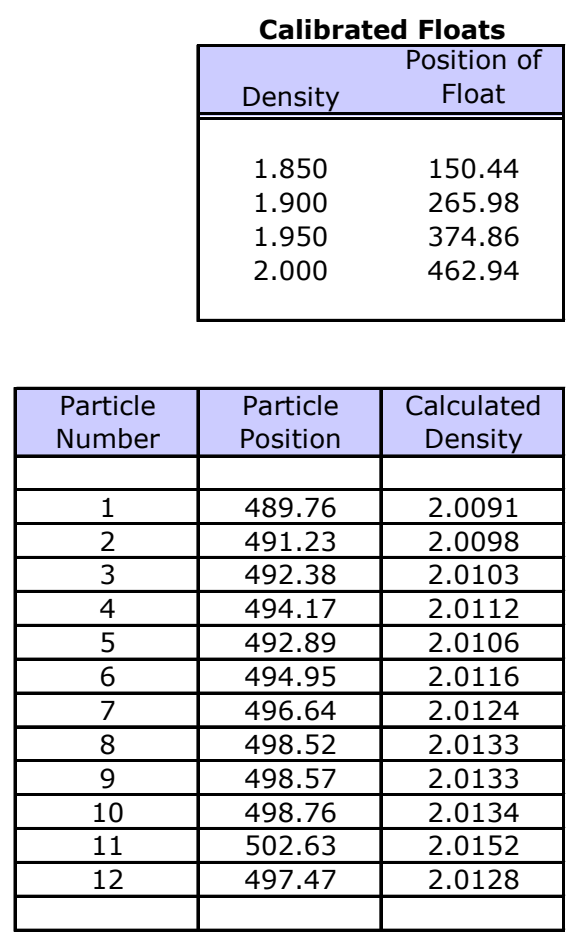

Figure 5-2: Density column data report for OPyC. Densities are in g/cc.

The density measured by this technique is expected to have a value between the envelope density and the skeletal density, depending on the porosity of the material and the extent to which the liquid penetrates the open pores. OPyC does have significant porosity, so it is uncertain where the density based on density column data falls relative to the envelope and skeletal densities. 


\title{
6 Optical Anisotropy Measurements
}

\author{
G. E. Jellison, Jr. and J. D. Hunn
}

Particles were mounted and polished to reveal the individual coatings and a series of optical anisotropy measurements were made using the two-modulator generalized ellipsometry microscope (2-MGEM). The 2-MGEM measured the average Mueller matrix in a $4 \mu \mathrm{m}$ diameter spot which was scanned over the specimen surface in two dimensions with a $2 \mu \mathrm{m}$ step size in each direction. With this data, various optical anisotropy parameters could be imaged with a $2 \times 2$ $\mu \mathrm{m}$ per pixel resolution. A data set containing 2-MGEM data for 182,000 spots was generated for each particle.

Images produced by the 2-MGEM were analyzed using a software tool developed for this project which allowed for individual pixels in the image to be selected and added to different lists. Using this tool, data was grouped together for the kernel (used for final data normalization), the IPyC layer and the OPyC layer. Data points can be selected using any of the optical parameter images. The diattenuation is often used. In some cases, such as when the diattenuation is near zero, it is more convenient to use the reflected intensity image in order to be able to identify the individual layers. Any one of the pictures can be displayed in the data sheet.

The diattenuation and the direction of the fast axis were measured. It was assumed that the diattenuation was the primary quantity, and it was set to be positive definite and was used to determine the direction of the fast axis. In the data sheet, the average and standard deviation (SD) of the data in each list was calculated. The average error (that is, the average of the error limits for each of the selected parameters measured at each point) was also calculated for the diattenuation. If there is a significant variation of the observed quantity around the layer, then the $\mathrm{SD}$ will be on the order of or greater than the average error, but if the quantity is uniform at all the selected points in the list, then the SD will be less than the average error.

In the PyC layers, the technique of characterizing crystalline anisotropy by measuring average optical anisotropy is based on the fact that the graphite structure possesses a high optical anisotropy. Ten separate particles were measured (Table 6-1). The IPyC layer had a significant diattenuation, $\mathrm{N}=0.0145 \pm 0.0008$. This corresponds to an optical anisotropy factor of $1.029 \pm 0.0016[\mathrm{OAF}=(1+\mathrm{N}) /(1-\mathrm{N})]$. The direction of the fast axis (which can range from $-90^{\circ}$ to $+90^{\circ}$, corresponding to the average in-plane direction of the $a-b$ plane) was roughly perpendicular to the growth direction. The net fast axis orientation was measured for each pixel. The standard deviation of the fast axis orientation for each particle was averaged to obtain a measure of graphene sheet alignment in the microstructure, which was called the average standard deviation of the fast axis orientation (ASD-FAO). The ASD-FAO was $7.9^{\circ} \pm 0.9^{\circ}$.

There was a smaller amount of optical anisotropy in the OPyC layer, again with the direction of the fast axis roughly perpendicular to the growth direction. Only six separate particles were analyzed (Table 6-2). The diattenuation was $0.0047 \pm 0.00099(\mathrm{OAF}=1.009 \pm 0.002)$. This was $32 \%$ of the diattenuation measured for the IPyC layer. The ASD-FAO was $26.1^{\circ} \pm 5.3^{\circ}$, which indicated only a weak partial alignment of graphene sheets perpendicular to the growth direction. 
It is important to note that the $\mathrm{IPyC}$ layer experienced the $\mathrm{SiC}$ deposition temperature and possible associated microstructural rearrangement, but the $\mathrm{OPyC}$ was not exposed to elevated temperature. As of the writing of this document, pyrocarbon microstructural change during $\mathrm{SiC}$ deposition has not yet been explored. Anisotropy results on OPyC may be less reliable than on IPyC due to rounding of the particle edge during cross-sectional polishing.

The measured anisotropies of the $\mathrm{ZrO} 2-500-\mathrm{AK} 2$ pyrocarbon layers were similar to those previously measured by the 2-MGEM for the German reference material. A total of 12 particles of German fuel were measured. The average of the average diattenuation for the IPyC layers was $0.0140 \pm .0016(\mathrm{OAF}=1.028 \pm 0.003)$. The average of the average diattenuation for the $\mathrm{OPyC}$ layers was $0.0080 \pm 0.0010(\mathrm{OAF}=1.016 \pm 0.002)$.

Table 6-1: IPyC optical anisotropy data based on 2-MGEM measurements

\begin{tabular}{|c|c|c|c|c|r|}
\hline Particle \# & $\begin{array}{c}\text { Average } \\
\text { Diattenuation }\end{array}$ & $\begin{array}{c}\text { Standard Deviation } \\
\text { of Diattenuation }\end{array}$ & $\begin{array}{c}\text { Average } \\
\text { Error }\end{array}$ & $\begin{array}{c}\text { Optical Anisotropy } \\
\text { Factor }\end{array}$ & ASD-FAO \\
\hline 1 & 0.0153 & 0.0036 & 0.0027 & 1.031 & 9.0 \\
2 & 0.0134 & 0.0032 & 0.0023 & 1.027 & 9.1 \\
3 & 0.0154 & 0.0032 & 0.0022 & 1.031 & 6.1 \\
4 & 0.0147 & 0.0037 & 0.0022 & 1.030 & 7.4 \\
5 & 0.0144 & 0.0032 & 0.0040 & 1.029 & 8.4 \\
6 & 0.0145 & 0.0032 & 0.0037 & 1.029 & 7.9 \\
7 & 0.0148 & 0.0037 & 0.0034 & 1.030 & 7.9 \\
8 & 0.0151 & 0.0032 & 0.0033 & 1.031 & 8.1 \\
9 & 0.0131 & 0.0032 & 0.0034 & 1.027 & 7.4 \\
10 & 0.0142 & 0.0031 & 0.0034 & 1.029 & 8.1 \\
\hline average & 0.0145 & 0.0033 & 0.0031 & 1.029 & 7.9 \\
\cline { 1 - 4 } st. dev. & 0.0008 & 0.0002 & 0.0007 & 0.0016 & 0.9 \\
\hline
\end{tabular}

Table 6-2: $\quad$ OPyC optical anisotropy data based on 2-MGEM measurements

\begin{tabular}{|r|r|r|r|r|r|}
\hline Particle \# & $\begin{array}{c}\text { Average } \\
\text { Diattenuation }\end{array}$ & $\begin{array}{c}\text { Standard Deviation } \\
\text { of Diattenuation }\end{array}$ & $\begin{array}{c}\text { Average } \\
\text { Error }\end{array}$ & $\begin{array}{c}\text { Optical Anisotropy } \\
\text { Factor }\end{array}$ & ASD-FAO \\
\hline 1 & 0.0049 & 0.0025 & 0.0041 & 1.010 & 27.7 \\
2 & 0.0049 & 0.0017 & 0.0033 & 1.010 & 19.6 \\
3 & 0.0028 & 0.0021 & 0.0039 & 1.006 & 35.1 \\
4 & 0.0058 & 0.0025 & 0.0039 & 1.012 & 22.1 \\
5 & 0.0046 & 0.0025 & 0.0038 & 1.009 & 26.3 \\
6 & 0.0049 & 0.0026 & 0.0041 & 1.010 & 25.9 \\
\hline average & 0.0047 & 0.0023 & 0.0039 & 1.009 & 26.1 \\
\hline st. dev. & 0.00099 & 0.0003 & 0.0003 & 0.002 & 5.3 \\
\hline
\end{tabular}




\title{
7 SEM Analysis
}

\author{
P.A. Menchhofer, J.D. Hunn, and I. Dunbar
}

\subsection{SEM of coated particles}

Each SEM analysis of ZrO2-500-AK2 was performed on an individual particle, so no statistical inferences about the microstructure can be made. Nonetheless, attempts were made to image "representative" particles so that SEM analysis should describe a typical ZrO2-500-AK2 particle. Figure 7-1 shows a typical particle cross-section with a bright kernel surrounded by a porous buffer surrounded by a dark gray IPyC layer, a bright $\mathrm{SiC}$ layer, and a dark gray OPyC layer.

No cracking or sudden microstructural transition was observed at the buffer/IPyC interface (Figure 7-2). The buffer layer had a substantial amount of porosity and perhaps slight porosity banding (Figure 7-3). The IPyC layer had significant porosity that was relatively randomly positioned; no porosity bands were observed in the IPyC layer (Figure 7-4). IPyC porosity bands have been previously observed in German TRISO fuel and historic U.S. TRISO experimental fuel. No consensus in the nuclear fuel community exists on the effect (if any) of IPyC porosity bands on fuel performance. It is hypothesized that a layered structure with bands of high porosity may result in a layer that is less permeable than one that has the same average envelope density but is more uniform throughout the thickness. The heterogeneous microstructure of the IPyC layer was studied using backscatter electron imaging (Figure 7-5). The flakes of carbon (dark gray) were formed by gas phase nucleation and later deposited onto the growing IPyC layer; the surrounding carbon material (light gray) grew on top of the carbon flakes before deposition or on top of the growing IPyC layer.

The interface between the IPyC and the $\mathrm{SiC}$ is shown in Figure 7-6. Extensive interfacial stitching without gaps was observed. The IPyC layer exhibited no significant increase in porosity at the IPyC/SiC interface. This interfacial structure has the potential to provide a strong bond between the IPyC and $\mathrm{SiC}$ layers under irradiation conditions.

The SiC layer had a fine grain structure with little porosity (Figure 7-7). The grains were predominantly asymmetric in shape, but a strong columnar microstructure was not observed. Figure 7-7 also enabled a side by side comparison of the IPyC/SiC and $\mathrm{OPyC} / \mathrm{SiC}$ interfaces. The IPyC/SiC interface (right boundary of SiC layer) was shown to have extensive interfacial stitching, while the OPyC/SiC interface (left boundary of SiC layer) was shown to have no discernable interfacial stitching. A high magnification view of the $\mathrm{OPyC} / \mathrm{SiC}$ interface is shown in Figure 7-8. Cracking can be observed along the OPyC/SiC interface (Figure 7-8). The OPyC layer had a similar porosity structure to the IPyC layer (Figure 7-9). 
ORNL/CF-05/12

Revision 1

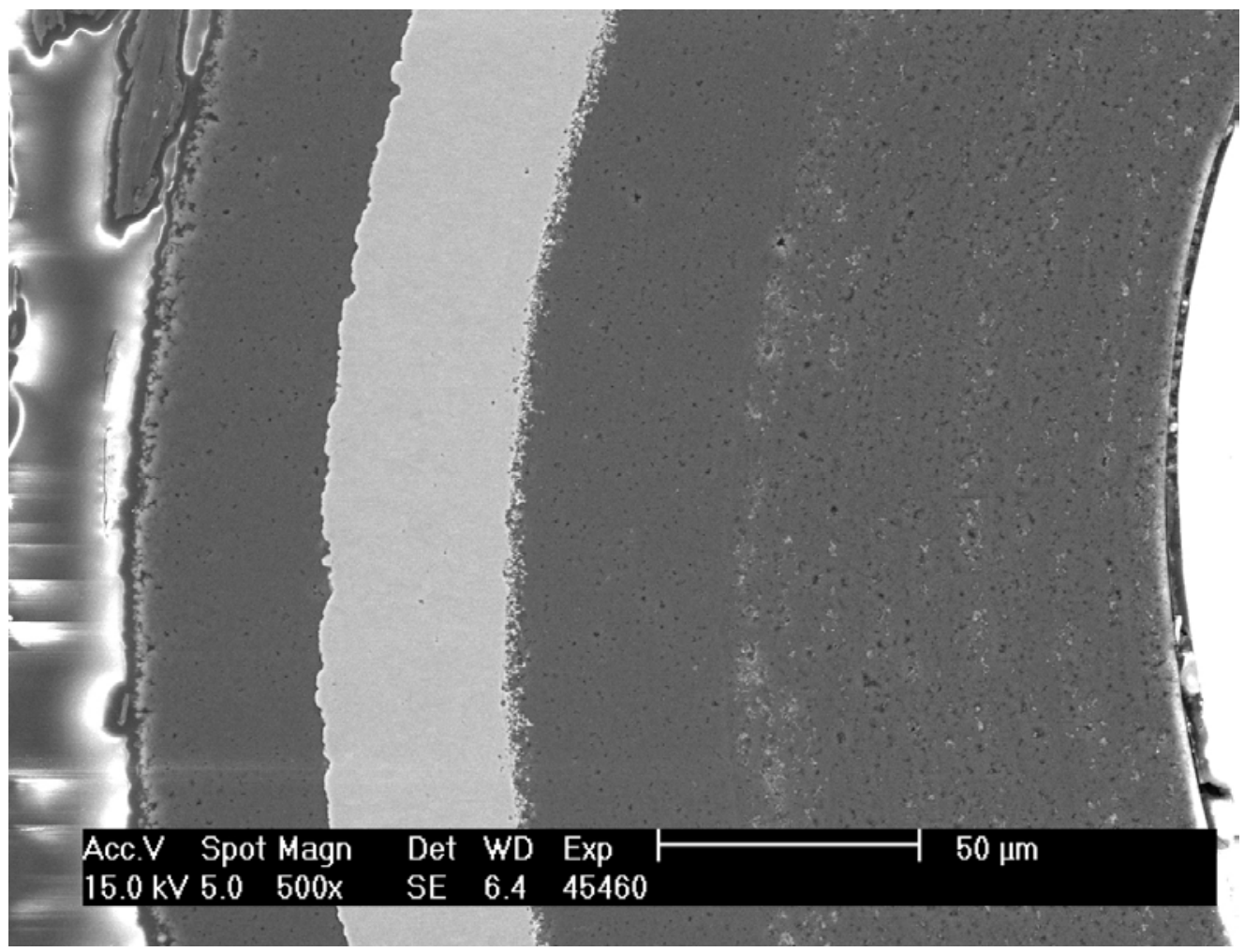

Figure 7-1: Typical coating layers for $\mathrm{ZrO} 2-500-\mathrm{AK} 2$ (secondary electron image).

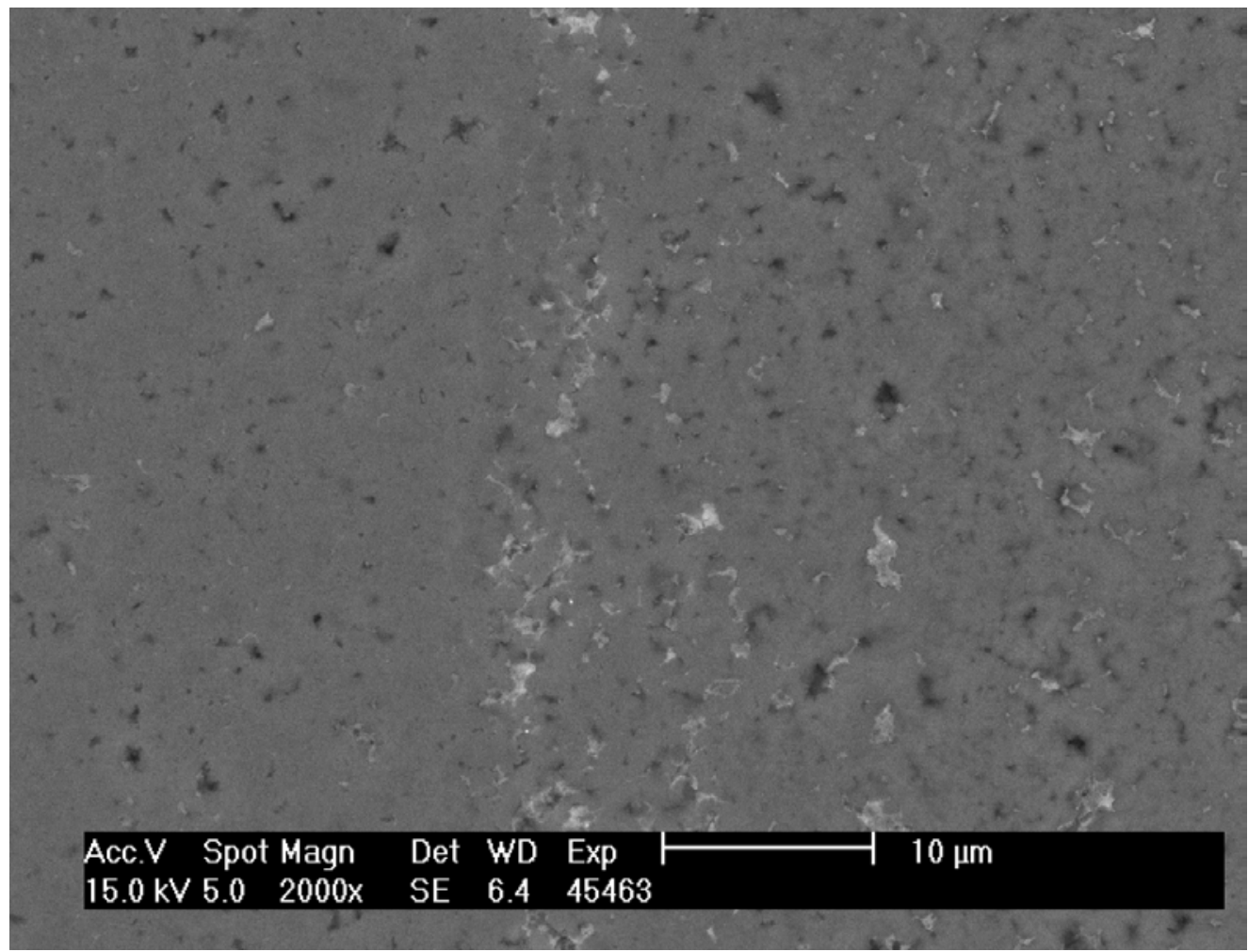

Figure 7-2: Buffer/IPyC interface in $\mathrm{ZrO} 2-500-\mathrm{AK} 2$ (secondary electron image). 
ORNL/CF-05/12

Revision 1

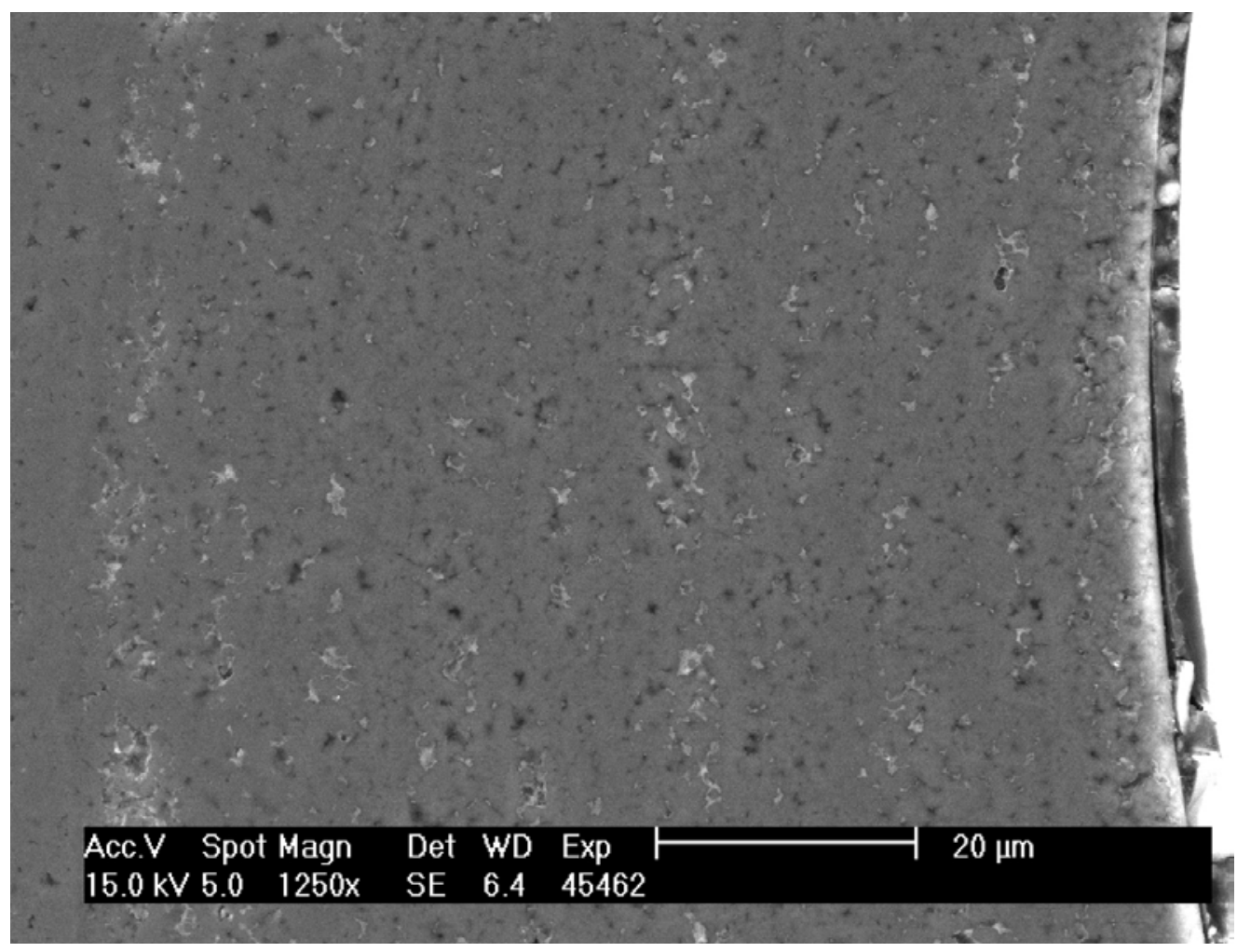

Figure 7-3: $\quad$ Buffer layer of $\mathrm{ZrO} 2-500-\mathrm{AK} 2$ (secondary electron image).

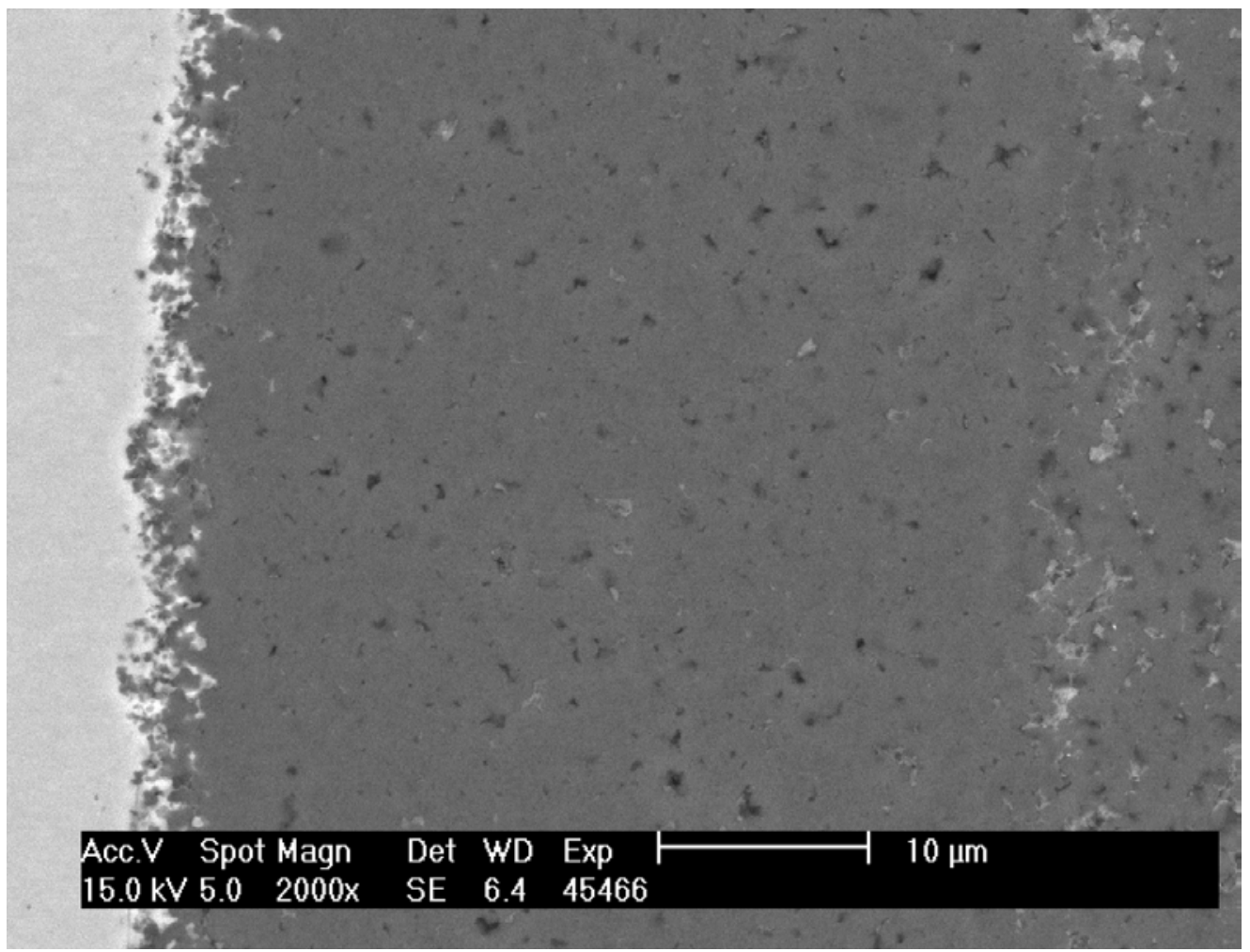

Figure 7-4: IPyC layer of $\mathrm{ZrO} 2-500-\mathrm{AK} 2$ (secondary electron image). 
ORNL/CF-05/12

Revision 1

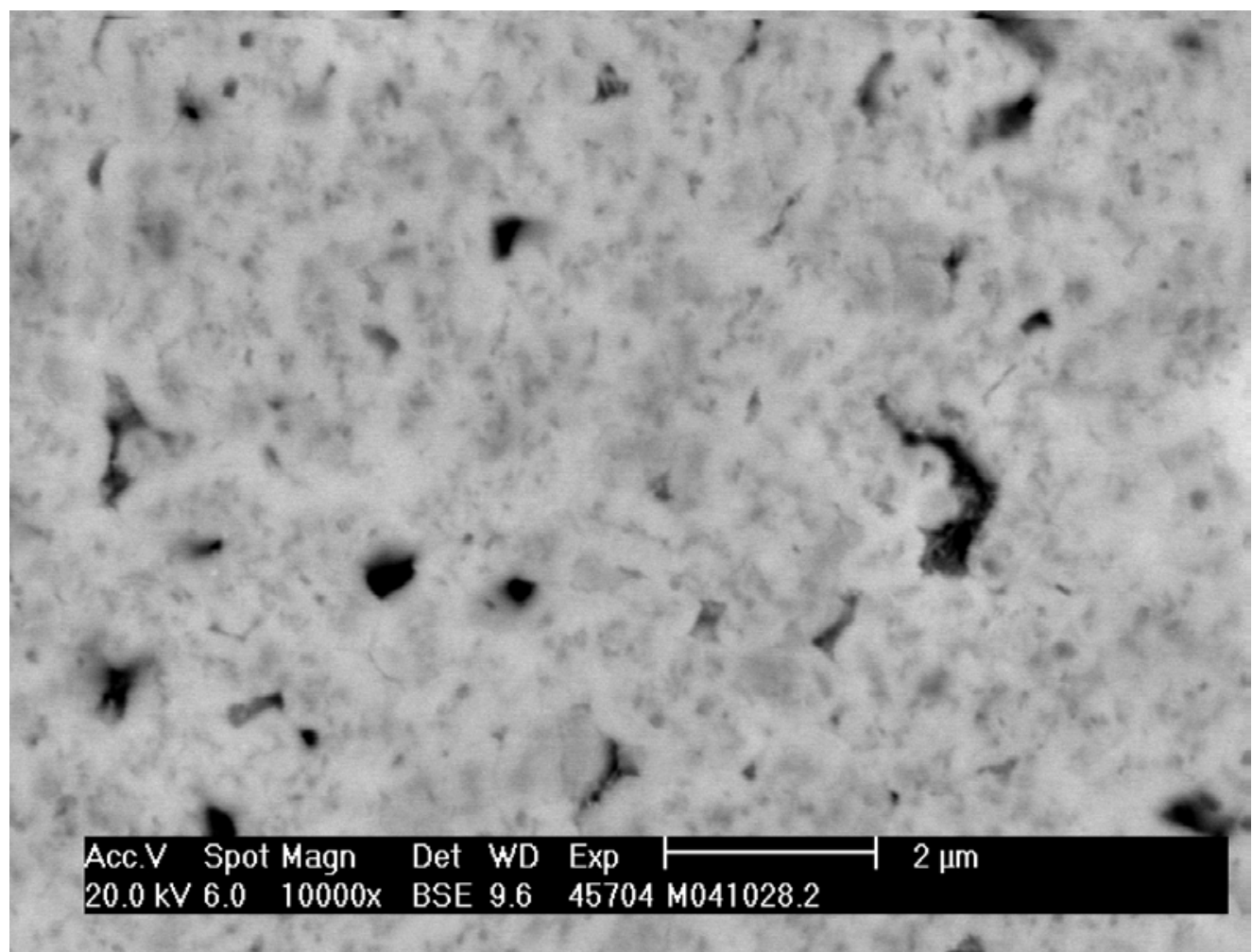

Figure 7-5: IPyC layer of $\mathrm{ZrO} 2-500-\mathrm{AK} 2$ (backscatter electron image).

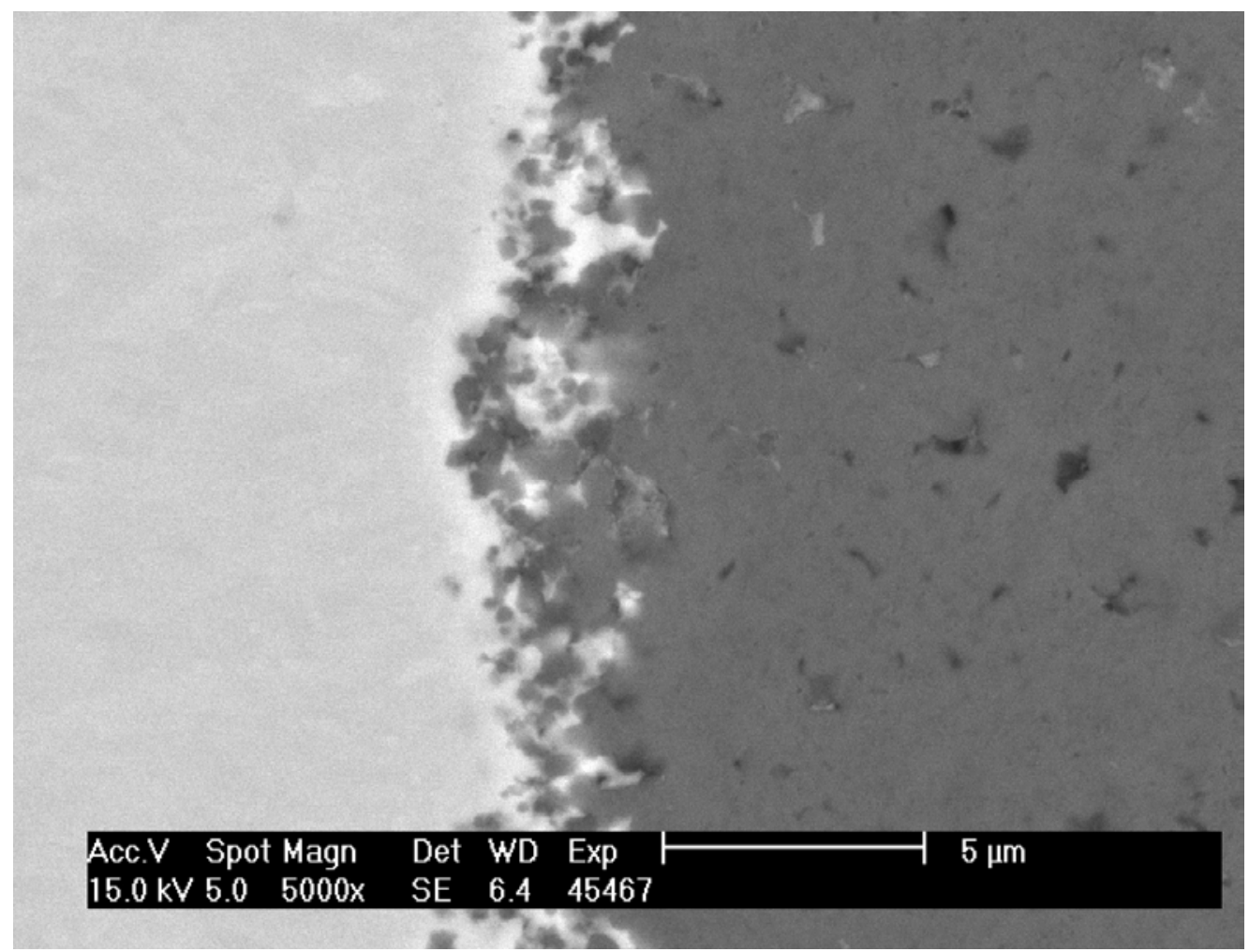

Figure 7-6: IPyC/SiC interface from $\mathrm{ZrO} 2-500-\mathrm{AK} 2$ ( $\mathrm{SiC}$ on left; secondary electron image). 
ORNL/CF-05/12

Revision 1

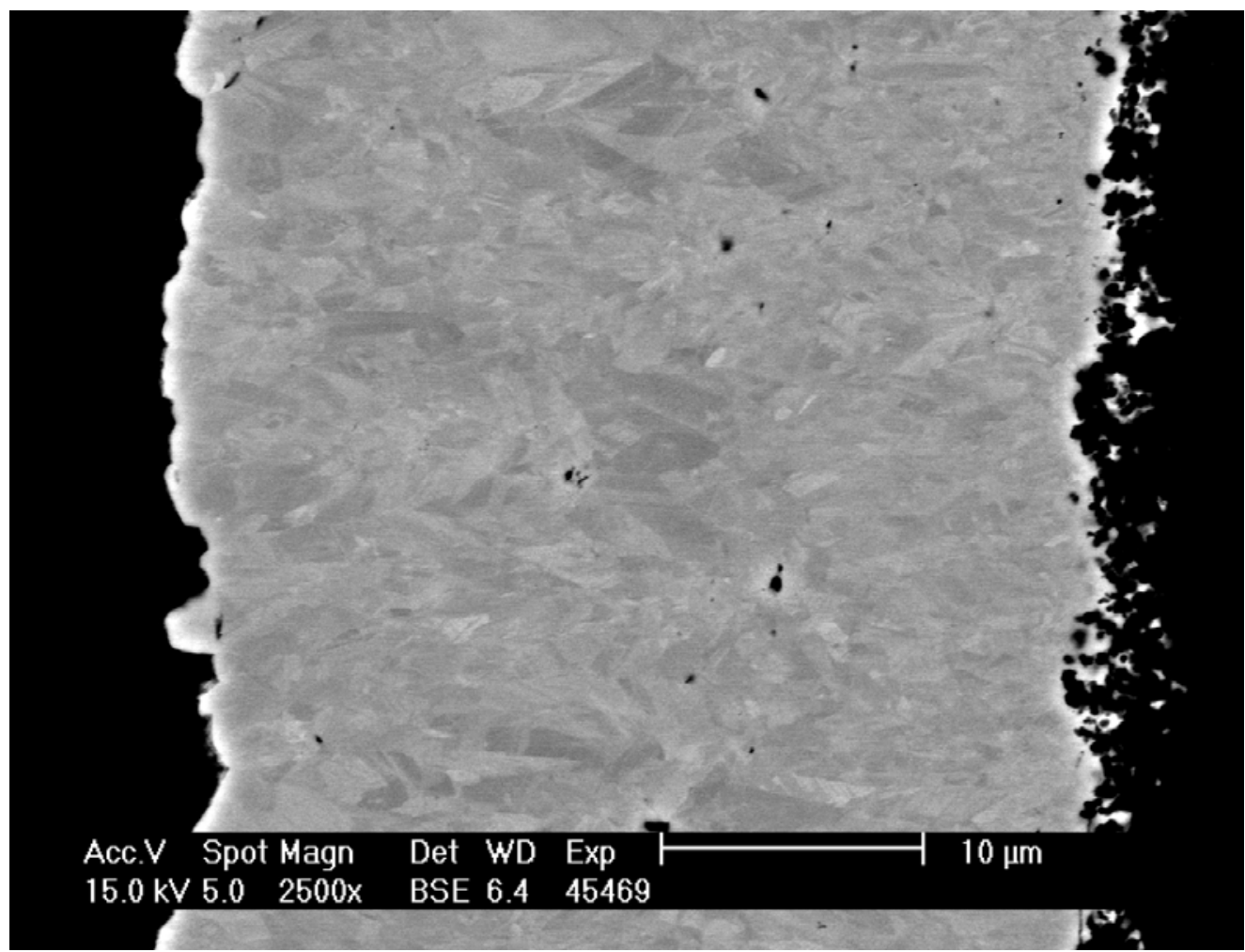

Figure 7-7: $\mathrm{SiC}$ layer of $\mathrm{ZrO} 2-500-\mathrm{AK} 2$ (backscatter electron image). Note the difference between the IPyC/SiC interface (right boundary) and the OPyC/SiC interface (left boundary).

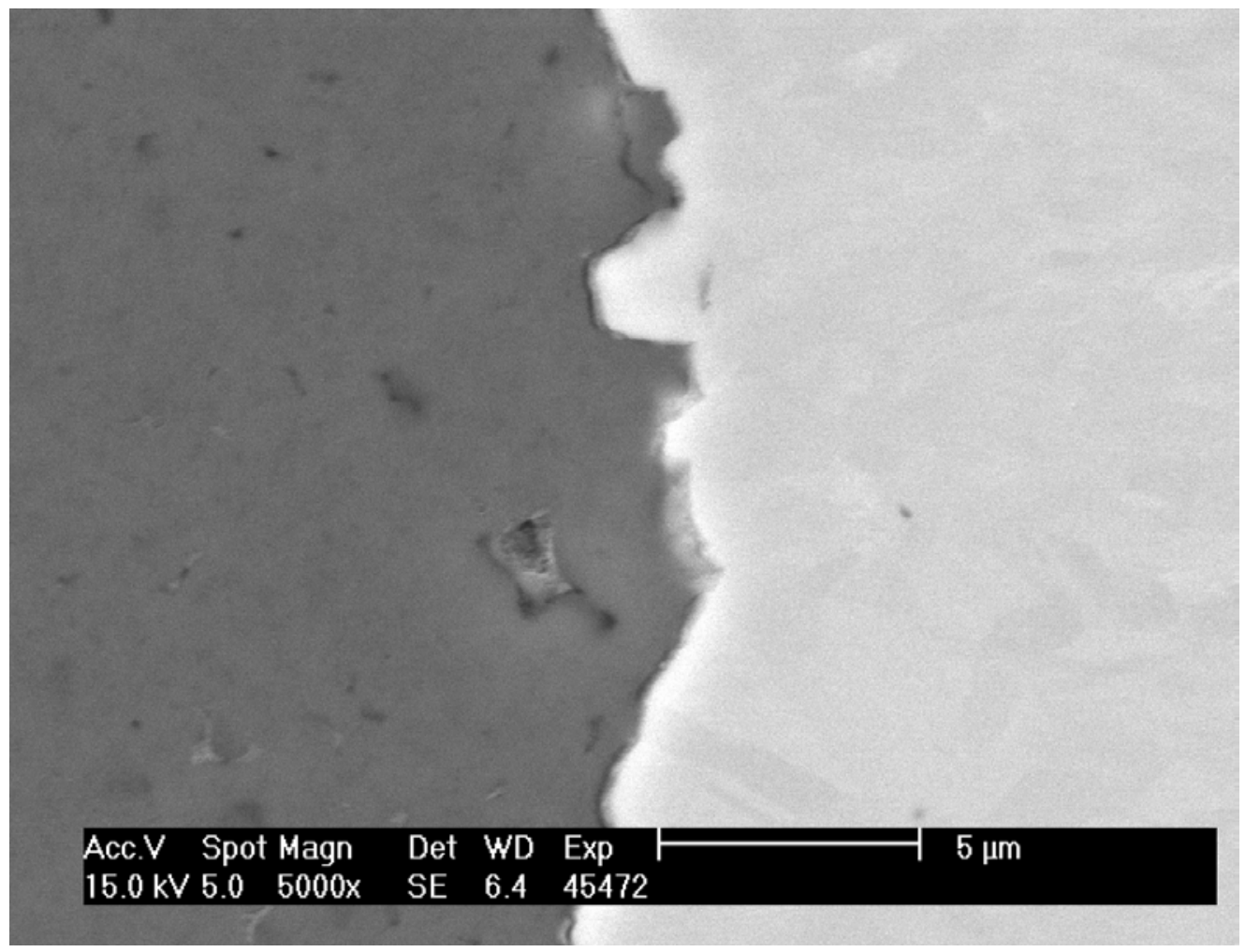

Figure 7-8: $\mathrm{SiC} / \mathrm{OPyC}$ interface from $\mathrm{ZrO} 2-500-\mathrm{AK} 2$ ( $\mathrm{SiC}$ on right; secondary electron image). 


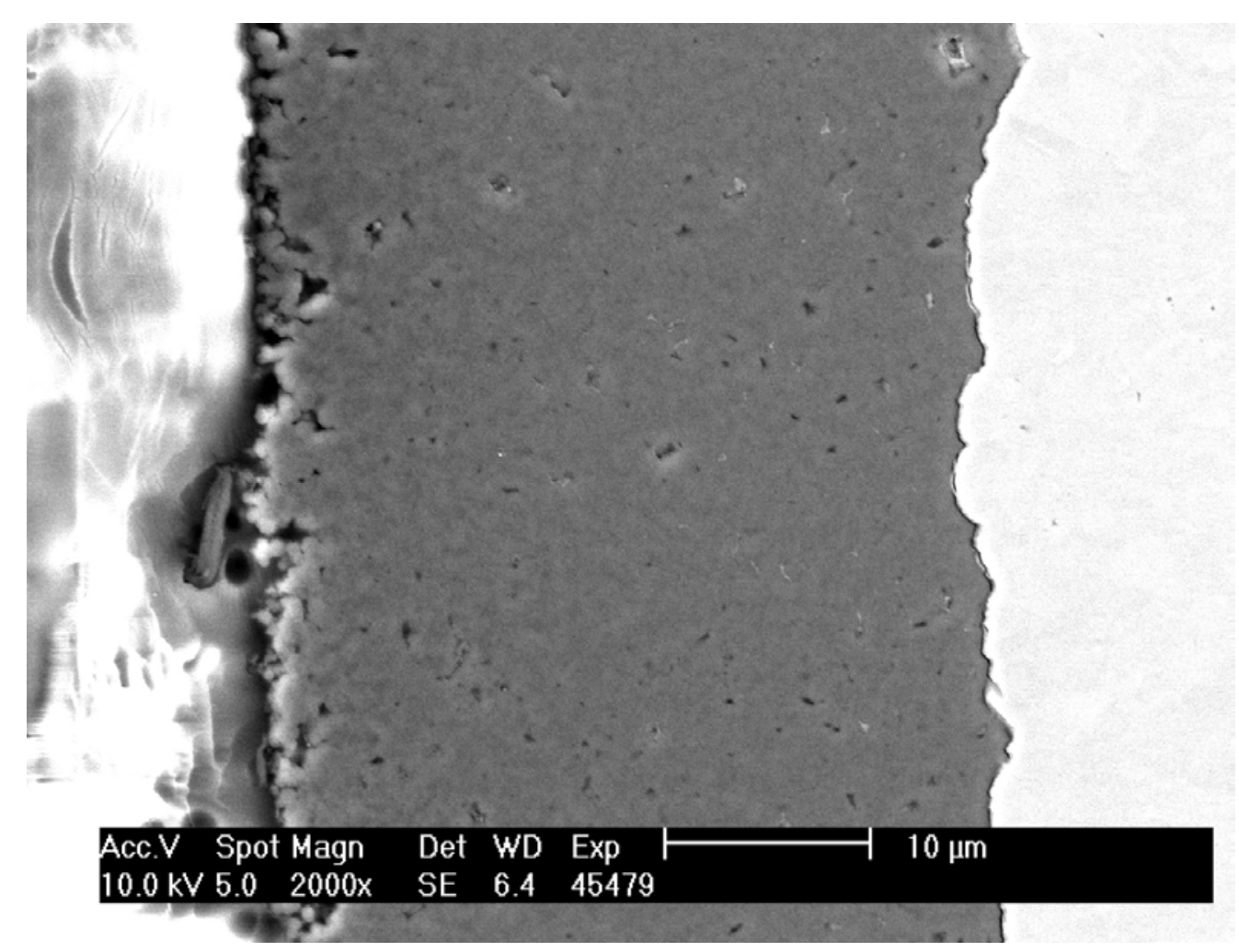

Figure 7-9: $\quad$ OPyC layer of $\mathrm{ZrO} 2-500-\mathrm{AK} 2$ (secondary electron image; SiC layer to the right).

\subsection{Grain size of $\mathrm{SiC}$ layer}

The grain size of the SiC layer was determined using ASTM standard E112-96. Grain boundaries were manually identified from SEM micrographs of the SiC layer. The ASTM grain size number, the grain number per square millimeter, and average grain area were approximated using a planimetric (Jeffrie's) procedure with a rectangular window (Figure 7-10 \& Figure 7-11). Grain boundary identification for fine-grained $\mathrm{SiC}$ was subjective, so all results should be taken as approximate descriptions of the $\mathrm{SiC}$ microstructure.

Table 7-1 summarizes the grain size results for the two micrographs of ZrO2-500-AK2 and the one micrograph of the German reference fuel. Data from German reference fuel were included for comparison. SiC grains near the IPyC/SiC interface were too small and indistinct to delineate for $\mathrm{ZrO} 2-500-\mathrm{AK} 2$. The grain sizes for $\mathrm{ZrO} 2-500-\mathrm{AK} 2$ and the German reference fuel were comparable. 
ORNL/CF-05/12

Revision 1

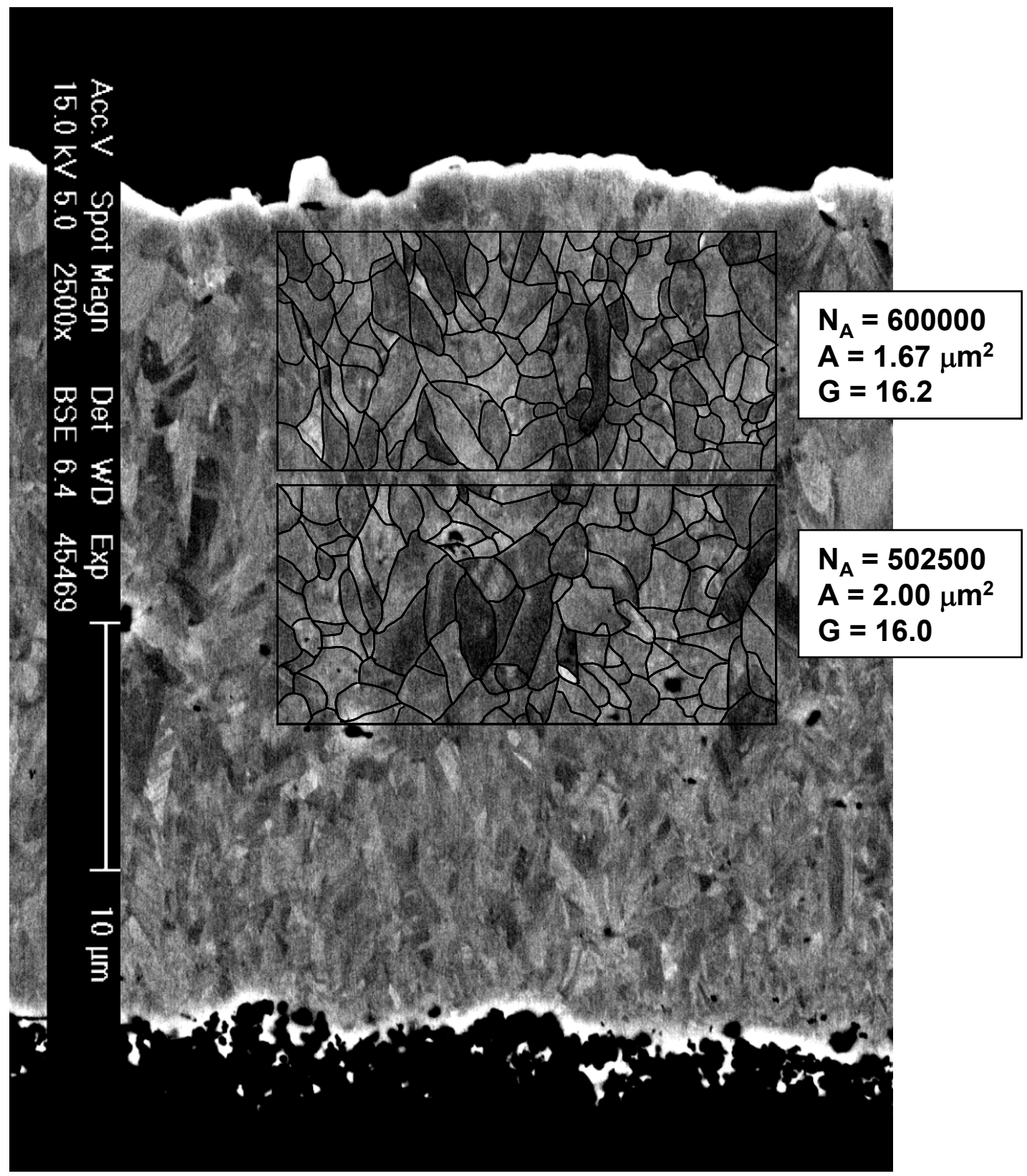

Figure 7-10: Grain size identification for $\mathrm{ZrO} 2-500-\mathrm{AK} 2$ at outer and middle regions of $\mathrm{SiC}$ layer. Grains in the inner region (close to IPyC) were too small and indistinct to reliably indentify. Image \#45469. 


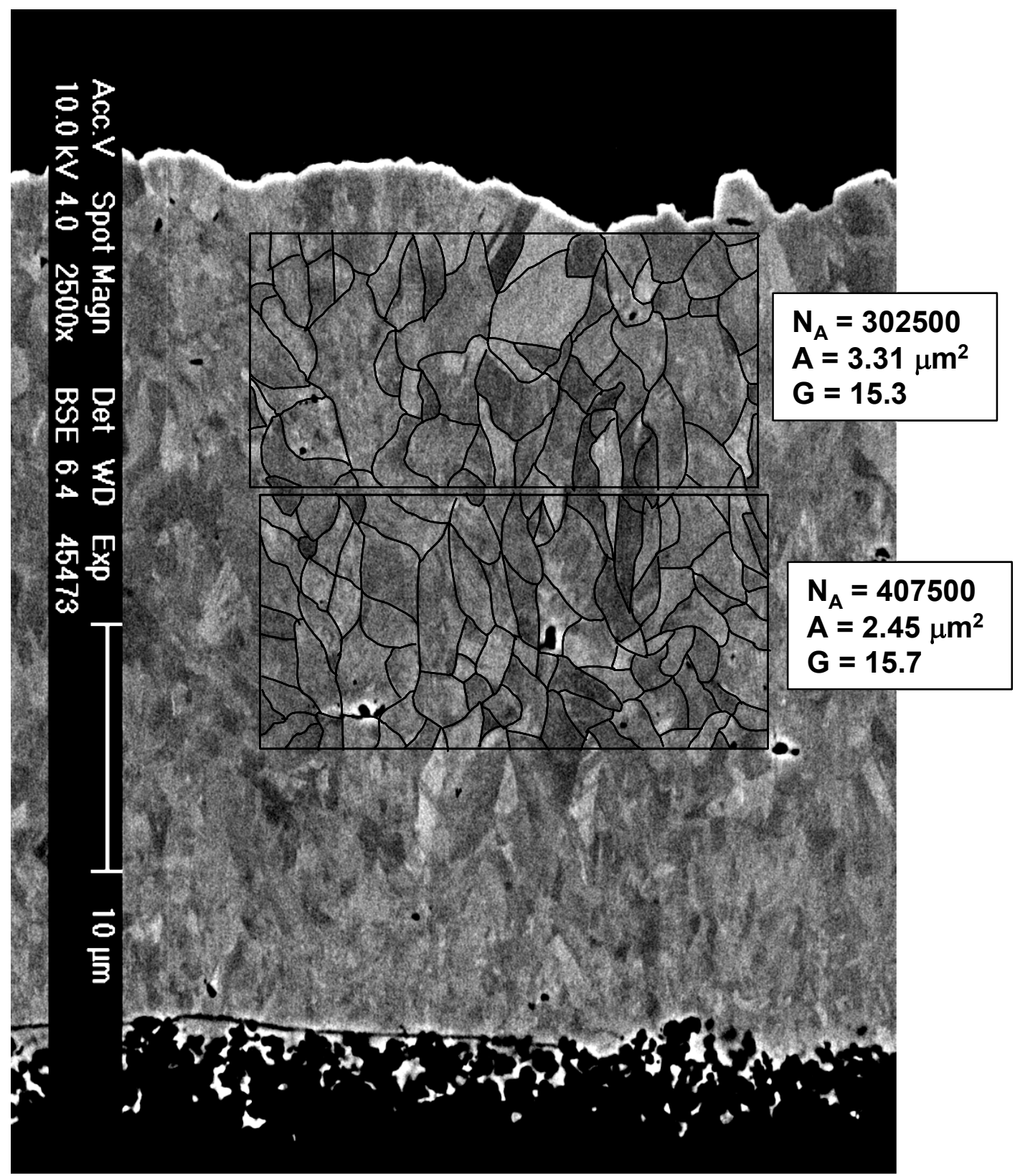

Figure 7-11: Grain size identification for $\mathrm{ZrO} 2-500-\mathrm{AK} 2$ at outer and middle regions of $\mathrm{SiC}$ layer. Grains in the inner region (close to IPyC) were too small and indistinct to reliably indentify. Image \#45473. 
ORNL/CF-05/12

Revision 1

Table 7-1: Results from $\mathrm{SiC}$ grain size analysis

\begin{tabular}{|c|c|c|c|c|}
\hline & Measured Area & $\begin{array}{l}\text { ASTM Grain } \\
\text { Size \#, G }\end{array}$ & $\begin{array}{l}\text { Grain number, } \\
\mathrm{N}_{\mathrm{A}}\left(\mathrm{mm}^{-2}\right)\end{array}$ & $\begin{array}{l}\text { Ave. Grain Area, } \\
\text { A }\left(\mu \mathrm{m}^{2}\right)\end{array}$ \\
\hline $\begin{array}{l}\text { AGR-06 Reference } \\
\text { (German reference fuel) }\end{array}$ & $\begin{array}{l}\text { Outer area of SiC layer } \\
\text { Middle of SiC layer } \\
\text { Inner area of SiC layer }\end{array}$ & $\begin{array}{l}15.4 \\
15.2 \\
15.4\end{array}$ & $\begin{array}{l}335000 \\
287500 \\
342500\end{array}$ & $\begin{array}{l}2.99 \\
3.48 \\
2.92\end{array}$ \\
\hline $\mathrm{ZrO}_{2}-500-\mathrm{AK} 2$ (Image \#45469) & $\begin{array}{l}\text { Outer } \\
\text { Middle } \\
\text { Inner }\end{array}$ & $\begin{array}{c}16.2 \\
16.0 \\
-\end{array}$ & $\begin{array}{c}600000 \\
502500 \\
-\end{array}$ & $\begin{array}{c}1.67 \\
2.00 \\
-\end{array}$ \\
\hline $\mathrm{ZrO}_{2}-500-\mathrm{AK} 2$ (Image \#45473) & $\begin{array}{l}\text { Outer } \\
\text { Middle } \\
\text { Inner }\end{array}$ & $\begin{array}{c}15.3 \\
15.7 \\
-\end{array}$ & $\begin{array}{c}302500 \\
407500 \\
-\end{array}$ & $\begin{array}{c}3.31 \\
2.45 \\
-\end{array}$ \\
\hline
\end{tabular}

